\title{
The life cycle of technological innovation systems
}

\section{Journal Article}

Author(s):

Markard, Jochen

Publication date:

2020-04

Permanent link:

https://doi.org/10.3929/ethz-b-000291404

Rights / license:

Creative Commons Attribution-NonCommercial-NoDerivatives 4.0 International

Originally published in:

Technological Forecasting and Social Change 153, https://doi.org/10.1016/j.techfore.2018.07.045 


\title{
The life cycle of technological innovation systems
}

\author{
Jochen Markard \\ Swiss Federal Institute of Technology Zurich, \\ Department of Management, Technology and Economics, \\ Weinbergstrasse 56/58, 8092 Zurich, Switzerland
}

July 2018

\begin{abstract}
The technological innovation systems framework is one of the key approaches in sustainability transition studies. However, scholars have so far mostly concentrated on the early stages of technology development and we know rather little about mature, or even declining TIS. Building on earlier insights from the industry and technology life cycle literatures, this paper introduces the key elements of a TIS life cycle framework and distinguishes between four key stages of TIS development: formation, growth, maturity and decline. An ideal TIS life cycle representation is suggested and three empirical examples of long-term TIS development and decline are discussed. It is argued that adopting a TIS life cycle perspective not only opens up important new issues for TIS studies but will also be essential for sustainability transition studies as it directs attention to technology decline and the role of public policies therein.
\end{abstract}

Keywords: innovation systems, industry life cycle, technology life cycle, sociotechnical transitions, context, emergence, decline

\section{Introduction}

Sustainability issues such as climate change, air pollution, lack of clean water availability, sanitation or depletion of national resources represent major challenges for societies. One way to address these challenges is through so-called sustainability transitions, i.e. fundamental changes in technologies, industries, organizations, consumption patterns and lifestyles with the goal of achieving more 
sustainable modes of production and consumption (Markard et al., 2012). The ongoing transformation in electricity sectors, where fossil and nuclear generation technologies are replaced by renewable energy generation, is an example of such a sustainability transition.

Two central issues in sustainability transitions are emergence and decline. Sustainable alternatives are supposed to emerge, while unsustainable technologies, policies, practices and ways of organizing decline. As many realworld transitions are in early stages of development, emergence has been the primary concern of transition scholarship and policymaking. Much attention has been devoted to study and support novel technologies, business models, organizations, infrastructures etc.

Meanwhile, some transitions have progressed into a stage, in which decline is becoming important as well (Markard, in press). In energy, technology decline has been supported by policies that accelerate the phase-out of coal and nuclear energy generation plants, or the use of incandescent light bulbs (Rosenbloom, in press; Stegmaier et al., 2014).

In transitions research, many studies have focused on emergence, while decline is a rather new topic of inquiry. This tendency is mirrored in the conceptual frameworks, some of which are explicitly geared towards innovation, emerging technologies and niche markets. As a result, there is now a need to improve existing transition frameworks and concepts, or to develop new ones, and to address later stages of development, including decline.

This paper focuses on the technological innovation systems (TIS) approach, which is a widely applied framework for analyzing technology development in the context of sustainability transitions (Bergek et al., 2008a; Hekkert and Negro, 2009; Markard et al., 2015). My overarching intention is to improve the TIS to be used for the next generation of transition studies. In this paper, I develop a new life cycle perspective for technological innovation systems, in order to capture all stages of technology development with the TIS approach.

When thinking about the TIS in the form of a life cycle, it is important to conceptualize it as a system whose structures and processes change as the underlying focal technology changes. This is important as it contrasts with other innovation system approaches that regard the system as rather stable. A life cycle perspective assumes that a TIS has a beginning and an ending and that there are substantial changes in between. In the formative phase, TIS structures emerge and there is also intentional strategic action, so-called system building (Musiolik et al., this issue). As the technology diffuses and matures, the TIS grows in size and its structures formalize, eventually even becoming rigid and path-dependent. In its decline phase, TIS structures weaken and break-up, organizations exit the TIS and both the TIS and the technology eventually vanish. 
Such a perspective on TIS is new. Even though the existing TIS literature acknowledges that a TIS can change (e.g. as it is shaped by system builders or policies in its early stages), scholars have so far not conceptualized the TIS as an entity that mirrors the dynamics of the corresponding technology. Taking a life cycle perspective may therefore create conflicts with earlier interpretations of the TIS concept. ${ }^{1}$ Below I try to be very explicit about the conceptual choices made throughout this paper, but there may still be issues that need be resolved in subsequent contributions.

In the following, I mobilize insights from the established literatures on industry life cycles and technology life cycles, which are concerned with identifying regularities in the development of industries (Klepper, 1997; McGahan et al., 2004) and technologies (Anderson and Tushman, 1990; Kaplan and Tripsas, 2008).

The paper starts by introducing the TIS framework and reviewing literatures on industry and technology life cycles (section 2). Section 3 introduces the main elements of the framework. Building on the existing literature, section 4 distinguishes four phases of TIS development. Section 5 presents an ideal-type TIS life cycle, while section 6 introduces three examples of technology decline (home entertainment, mobile communication and lighting) and interprets them from a TIS life cycle perspective. Finally, this is followed by a discussion and conclusion.

\section{Theoretical background}

The field of sustainability transition studies is a rapidly developing area of research that addresses long-term, fundamental transformations in sectors such as energy, transport or food, which are associated with sustainability goals (Markard et al., 2012). Sustainability transitions research is based on systems thinking, emphasizes the interrelatedness of social, technical, institutional and political changes, and highlights path-dependency and lock-in (Geels et al., 2016a). Many transition scholars address grand sustainability challenges such as climate change, clean air or resource conservation while adopting a widely shared normative assumption that most established sectors need to change fundamentally to become more sustainable in the long run (Geels et al., 2017). As a consequence, public policies play a major role and sustainability transitions can be viewed as purposive transitions towards specific goals.

1 One such interpretation is that a 'healthy' TIS will constantly generate innovation, thereby surviving major technological disruptions. I will come back to this in the discussion. 
A comprehensive transition policy agenda does not only address emergence but also decline (Kivimaa and Kern, 2016). As part of the ongoing energy transition, governments in the UK, Germany, Switzerland, Ontario/Canada and elsewhere have formulated policies that target the phase-out of coal or nuclear as unwanted power generation technologies, and the EU and other states have implemented bans on incandescent light bulbs.

In the transitions literature, only few studies have focused on decline so far (Johnstone and Hielscher, 2017; Rosenbloom, in press; Stegmaier et al., 2014; Turnheim and Geels, 2012). And while there are many studies on industry decline more generally (Lamberg et al., 2017), they typically apply a regional focus, i.e. they study the decline of a particular industry in a particular region or country. Examples include the decline of the British coal and textile industries (Lazonick, 1983; Turnheim and Geels, 2012).

As a result, there is clearly a gap. More studies are needed focusing on decline in general and also addressing decline at a global level. It is with regard to the latter that technology decline is particularly relevant. If just one or two countries cease coal-fired power generation, for example, this would not have a significant global impact. Specifically, established coal extraction and shipping industries or heavy engineering industries (for power production) will not be affected. However, if technologies such as nuclear, coal or incandescent light bulbs decline globally, this is a different story.

Next to the empirical gap, we also have to revisit established conceptual frameworks in transition studies. Some of them such as strategic niche management or technological innovation systems are very much geared towards studying emergence. This presents a conceptual gap as well.

In the following, I concentrate on the technological innovation systems (TIS) approach for several reasons. First, it is a conceptually sound systems approach, which is well suited to cover technological, organizational and institutional changes and their respective interactions. Second, it can be linked directly to an unwanted technology (e.g. coal-fired power production) while also covering broader industries and supply chains linked to this technology. Third, TIS scholars have already started to engage with the global dimension of innovation systems and the complex relationships between local and global technology dynamics (Binz and Truffer, 2017). Finally, the TIS approach has proven to be very fruitful when informing policymakers about targeted interventions to foster technology development. In agreement with Kivimaa and Kern (2016), I therefore expect that the TIS approach can also be used to specifically inform policymakers who want to accelerate technology decline. 


\subsection{Technological innovation systems}

\subsubsection{Conceptual foundations}

The technological innovation systems approach has been developed to explain the emergence and development of new technologies. The approach is also used to assess the performance of a selected technological innovation system and to make policy recommendations of how to improve it, often at a national level (Bergek et al., 2008a; Carlsson et al., 2010; Hekkert et al., 2007).

A technological innovation system can be conceptualized as a set of networks of actors and institutions that jointly interact in a specific technological field and contribute to the generation, diffusion and utilization of variants of a technology and/or product (Bergek et al., 2015; Carlsson and Stankiewicz, 1991; Markard and Truffer, 2008). The key elements of a TIS are thus actors, institutions and networks. Actors include technology manufacturers, suppliers, vendors, research institutes, associations, public authorities, NGOs etc. Institutions comprise of formal structures such as regulations, technology standards or public policies as well as informal structures such as collective expectations, cognitive frames, user practices, social norms or culture. Networks include inter-organizational networks for knowledge exchange as well as formal alliances and advocacy coalitions.

The TIS approach is based on evolutionary theorizing and systems theory. The basic causal mechanism is a close interaction of system elements, which in the case of complementary elements generates positive feedback effects ${ }^{2}$ (Bergek et al., 2008a). As a result, institutional structures emerge at the system level, which again affect further development of the technology (Markard et al., 2015). The TIS framework pays particular attention to both formal and informal institutions. Besides the relevance of institutions, the TIS approach acknowledges strategic and entrepreneurial action, including competition and collaboration of a broad range of organizations, directed at technology development and system building (Hellsmark and Jacobsson, 2009; Kukk et al., 2015; Musiolik et al., this issue).

To analyze TIS performance, scholars have suggested a set of key processes, socalled system functions, to be used as performance indicators (Bergek et al., 2008a; Bergek et al., 2008c; Hekkert et al., 2007; Jacobsson and Bergek, 2011; Johnson, 2001). These include i) knowledge development and diffusion, ii) influence on the direction of search, iii) entrepreneurial experimentation, iv) market formation, v) legitimation, vi) resource mobilization and vii) development of positive externalities (Bergek et al., 2008a). All functions need

2 An example of these effects is what Arthur (1987) refers to as increasing returns of adoption'. 
to show a certain level of activity and quality for the system to perform well. Scholars have developed performance indicators for the different functions with the goal of identifying system weaknesses and to inform policymakers on how to foster the development of a particular technology.

A technological innovation system is situated in a larger context, which can be understood as an infinite repertoire of 'other' actors, networks, institutions and technologies (Bergek et al., 2015; Markard et al., 2016). Of particular interest are semi-coherent context structures that also exhibit systemic characteristics. These include other TIS, other sectors and industries, geographical context structures as well as political, educational or financial systems (Bergek et al., 2015; Wirth and Markard, 2011). Changes in context (e.g. shifting policy priorities or emergence of complementary technologies) affect the focal TIS, meanwhile the TIS may also affect its context, as shown for the case of biogas technologies which had positive and negative repercussions for the agricultural sector (Markard et al., 2016).

\subsubsection{Existing ideas on different phases of TIS development}

In its beginnings, the TIS concept was abundantly used to study existing industries (Carlsson, 1997; Carlsson and Jacobsson, 1994), with the goal of assessing an industry's ability to generate novel technologies and to make recommendations to increase innovation performance. In that regard, early TIS studies were very similar to those applying national, regional or sectoral innovation system perspectives. They all implicitly assume that the underlying system structures are rather stable and already in place at the time of the analysis.

Recently, TIS scholars have become more and more interested in novel technologies that are associated with the formation of new industries ${ }^{3}$ such as wind and photovoltaic energies (e.g. Bergek and Jacobsson, 2003; Bergek et al., 2008c; Jacobsson and Bergek, 2004; Negro et al., 2007; Negro and Hekkert, 2008), bringing a new angle to TIS studies. In such cases, not just the focal technology is emerging but also the specific organizations, institutions and networks that support this technology. In other words, there is a co-development of the TIS and its underlying focal technology.

3 Technological innovation systems and industries have similarities. They focus on a specific product (industry) or technology (TIS) and can be defined at a similar level of aggregation. At the same time, there are conceptual differences with the TIS highlighting systemic interdependencies and institutional structures. The notion of industry typically points to firms that manufacture the same product (e.g. automobile industry), while the TIS includes a broader range of actors such as universities, associations, or NGOs. Moreover, a TIS may also include suppliers and service providers, i.e. capture parts of a larger value network that supports the focal technology. As a consequence, one TIS may overlap and interact with several industries. 
This understanding is essential for a TIS life cycle perspective. The central idea is that both TIS and its focal technology emerge, mature and decline together, and when a technology ceases to exist so does the corresponding TIS. ${ }^{4}$ Of course, this does not mean that all former TIS actors vanish. Some firms may live on well, but they exit the focal TIS and turn to other business fields.

Such a perspective clearly contrasts with the 'classic' understanding of innovation systems as largely stable configurations that can even be mobilized by firms to survive major technological shifts. At the same time, the seed for the idea of a TIS changing as the underlying technology matures has already been planted in TIS literature many years ago.

Building on the industry and technology life cycle literatures, Bergek and Jacobsson (2003) distinguished a phase of experimentation with competing technological variants, low market volumes, frequent entries and exits and a high degree of uncertainty, and a growth phase, in which technology diffuses widely and the market expands rapidly. These ideas were detailed later by Bergek et al. (2008) who suggest distinguishing a formative phase and a growth phase. The former is characterized by

“... constituent elements of the new TIS begin to be put into place, involving entry of some firms and other organizations, the beginning of an institutional alignment and formation of networks. A rudimentary structure is formed." (Bergek et al., 2008; 419).

The authors also propose a set of criteria for identifying the formative phase, cf. Box 1. Bento and Wilson (2016) go a step further as they define other criteria such as the first significant prototype or a certain share of adoption to determine the beginning and end of the formative phase of a TIS. Studying more than a dozen technologies, they find a high variance in the duration of the formative phase for different TIS, from less than 5 to more than 50 years (ibid.).

In contrast to the formative phase, the growth phase is viewed as being qualitatively different because

"... the focus shifts to system expansion and large-scale technology diffusion through the formation of bridging markets and subsequently mass markets" (Bergek et al., 2008; 420).

4 A technology vanishes: This does not imply that the underlying knowledge is gone (which is rather not plausible) but that the product(s) in which it is incorporated are not produced and used anymore and that the former producers, suppliers and customers have either ceased to exist or turned to other products. 
- “... we rarely escape formative periods that are shorter than a decade ...;

- large uncertainties prevailing as regards technologies, markets and applications;

- $\quad$ price/performance of the products being not well developed;

- a volume of diffusion and economic activities that is but a fraction of the estimated potential;

- demand being unarticulated; and

- absence of powerful self-reinforcing features (positive feedbacks) and weak positive externalities."
Box 1: Features of the formative phase of a TIS (Bergek et al. 2008, p. 419)

In the growth phase the system is said to develop in a selfsustaining way due to a "chain reaction of positive feedback loops ... setting in motion a process of cumulative causation" (Jacobsson and Bergek, 2004, p. 823).

These early phase distinctions

build the basis for the subsequent introduction of a TIS life cycle perspective that goes beyond these two phases of development and also includes maturation and decline. Similar life cycle concepts have already been proposed in the literatures on industry and technology life cycles, which are briefly introduced in the next section below.

\subsection{Industry life cycle}

The literature on industry life cycles (ILC) is concerned with recurring patterns in the emergence and maturation of industries, and the resulting implications for firm strategies (Gort and Klepper, 1982; Klepper, 1997; Peltoniemi, 2011). It is closely related to the literatures on product life cycles and technology life cycles, and scholars have even used these terms interchangeably (Taylor and Taylor, 2012).

The central message from ILC studies is that many industries show similarities as they evolve over time and that these patterns are driven endogenously, e.g. by the shift from product to process innovation and the advantages of spreading $R \& D$ costs over large quantities (Klepper, 1997). Emerging industries start with just a few actors, ill-defined products and a high level of uncertainty. This phase is followed by a period of rapid growth in which standards and value chains form, many new actors enter and sales take off. At some point, markets become saturated, growth slows down, competition increases and there is a shakeout with many firms leaving the industry. This leads to a final phase of stabilization. 
In their analyses, ILC scholars focus on firms, more specifically on populations of firms competing in the same market. ${ }^{5}$ As a consequence, entry/ exit rates, market size and market shares, survival rates, or the vertical structure of firms are central dimensions in ILC studies (Agarwal and Tripsas, 2008; Klepper, 1997). A central explanatory element of the industry life cycle is the product life cycle (PLC) and the shift from product to process innovation:

"... the essence of the PLC is that initially the market grows rapidly, many firms enter, and product innovation is fundamental, and then as the industry evolves output growth slows, entry declines, the number of producers undergoes a shakeout, product innovation becomes less significant, and process innovation rises." (Klepper, 1997; 149)

Despite a large number of industries showing regularities in their development, ILC scholars have also acknowledged that industries deviate from the typical pattern, e.g. as they do not experience a shakeout (Klepper, 1997), or show continuous product innovation also in later years (Davies, 1997). Examples include complex product systems (CoPS), service industries and cultural industries (Peltoniemi, 2011). Among others, major differences in industry structures, innovation patterns (Pavitt, 1984), product or technology characteristics have been suggested as an explanation (Huenteler et al., 2016; Klepper, 1997).

ILC studies are rooted in economics and industrial organization (Gort and Klepper, 1982), but there are also overlaps to management studies and organizational ecology. Especially work in the latter tradition has pointed to the importance of institutional structures and social processes such as legitimacy creation, or the generation of new product categories (Agarwal and Tripsas, 2008; Suarez et al., 2015).

To conclude, the ILC literature highlights competition and shakeouts together with the shift from product to process innovation as key features of the industry life cycle. Researchers have suggested a range of criteria to measure industry dynamics and collected impressive empirical evidence of regularities. ILC scholars have shown a great interest in industry emergence as well as maturation, but have focused less on decline. Also, especially in early work there is a tendency to neglect institutions and institutional contexts (e.g. differences across regions) as well as interactions across industries (Agarwal and Tripsas, 2008; McGahan et al., 2004).

\footnotetext{
5 In fact, this idea is at the core of the understanding of what constitutes an industry.
} 


\subsection{Technology life cycle}

The technology life cycle (TLC) literature focuses on regularities in the emergence and maturation of technologies (Anderson and Tushman, 1990; Taylor and Taylor, 2012; Tushman and Rosenkopf, 1992). It highlights that technological change is the result of a complex interplay of "technical, economic, social, political and organizational processes" (Tushman and Rosenkopf, 1992; p.312). The technology life cycle is portrayed as a sequence of technological discontinuity, an era of ferment, the emergence of a dominant design and an era of incremental change. In the era of ferment, different technological variants compete, performance characteristics are unclear and uncertainty is high. When a dominant design emerges, both technological variation and uncertainty decrease. In the subsequent phase of incremental changes, key challenges are identified, and performance characteristics are settled.

For TLC scholars, technology and the strategic actions of firms directed at the development of the technological field are in the focus. Key dimensions of analysis include technological variation, technology performance, and the magnitude of innovation, i.e. incremental vs. discontinuous. Central concepts are dominant designs and technology standards, which may be analyzed at different levels of aggregation (Murmann and Frenken, 2006). Further elements of the TLC approach are S-shaped curves for technology diffusion (Taylor and Taylor, 2012), or performance improvement, as well as the wave model of product and process innovation (Utterback and Abernathy, 1975).

TLS scholars have pointed to differences between technologies, distinguishing e.g. non-assembled products, assembled products and assembled systems (Tushman and Rosenkopf, 1992). This opens up the possibility, to study interrelated products and technologies and how changes in one component can possibly affect technology dynamics in another. Tushman and Rosenkopf (1992) also highlight that the impact of sociopolitical processes on technology development depends both on the type of technology and on the phase of the cycle.

The TLC literature is theoretically based on evolutionary theorizing, with explicit attention given to the social and political processes influenced by various kinds of actors affecting the emergence of dominant designs. This is an interesting difference to the ILC literature, which primarily focuses on the competition of firms.

"We argue that because a single technological order rarely dominates alternative technologies across critical dimensions of merit, community level sociopolitical processes adjudicate among feasible technical/economic options. The closing on critical dimensions of merit is shaped by a process of compromise and accommodation between suppliers, vendors, customers and governments." (Tushman and Rosenkopf, 1992; 322) 
Despite the fact that technology standards and dominant designs are central in TLC studies, TLC scholars again tend to pay less attention to general institutional dynamics or to the effects of different institutional environments (Nelson, 1995). Exceptions include some of the more recent work, which highlights, among other things, how thinking and collective frames affect technology development (Kaplan and Tripsas, 2008).

To summarize, the TLC literature places dominant designs and technology performance center stage. Even though firms are in the focus, TLC scholars look into a broader range of actors and their strategies are directed at establishing a dominant design. Again, the focus is on the emergence of (discontinuous) innovation, not on technology decline. The TLC literature acknowledges the complexity that arises if technologies are systemic assemblies of different components produced by different industries. Institutional structures and variations in context have received less attention.

\subsection{Summary and next steps}

The above life cycle literatures consistently report that there are regularities in the emergence and maturation of industries and technologies. These include fluid stages with a high degree of variety and uncertainty in the beginning, followed by a more rigid stage characterized by incremental innovation, high entry barriers and low uncertainty later on. These findings form the basis when distinguishing and describing the different phases of the TIS life cycle in section 4. Formative and growth phases are in line with the existing TIS literature and also reflect the dynamics described in ILC approaches (a phase of high uncertainty and variety followed by a period of rapid growth). The mature TIS corresponds to ILC's phase of stabilization and the phase of incremental changes in the TLC literature.

The review also shows that there has been much attention on the emerging and mature stages of development, while the decline stage was studied much less. ${ }^{6}$ Given the interest in decline, in the context of sustainability transitions, this is clearly a gap and more conceptual and empirical work is warranted here. In this paper, I describe the decline in parallel with the other phases (cf. Table 2, section 4), but it is important to note that these descriptions are tentative.

Also note that ILC and TLC have largely generated similar or complementary findings. In fact, the two strands of literature are very much compatible and they have overlapping theoretical roots, e.g. in evolutionary economics. And even

6 This does not mean that decline does not play a role in prior literature. Especially in TLC, which is concerned with incumbent firms failing when confronted with disruptive changes, decline and disruption are central elements. 
though they have different foci, they share a common interest in the fate of firms with respect to both industrial change and technological discontinuities.

Table 1: Comparison of ILC, TLC and the TIS approach

\begin{tabular}{|c|c|c|c|}
\hline & Industry Life Cycle & Technology Life Cycle & $\begin{array}{l}\text { Technological Innovation } \\
\text { Systems }\end{array}$ \\
\hline Focus & $\begin{array}{l}\text { Firms; patterns in indu- } \\
\text { stry development }\end{array}$ & $\begin{array}{l}\text { Technology; patterns in } \\
\text { technology development }\end{array}$ & $\begin{array}{l}\text { Technology dynamics; } \\
\text { system performance }\end{array}$ \\
\hline $\begin{array}{l}\text { General } \\
\text { interest }\end{array}$ & $\begin{array}{l}\text { Understand and survive } \\
\text { industry change; } \\
\text { suggestions for manage- } \\
\text { ment }\end{array}$ & $\begin{array}{l}\text { Understand and survive } \\
\text { discontinuities; } \\
\text { suggestions for manage- } \\
\text { ment }\end{array}$ & $\begin{array}{l}\text { Understand technology } \\
\text { dynamics; sustainability; } \\
\text { suggestions for policy }\end{array}$ \\
\hline $\begin{array}{l}\text { Key } \\
\text { Concepts }\end{array}$ & $\begin{array}{l}\text { Industry; entry/exit, } \\
\text { shakeout; } 3 \text { stages of the } \\
\text { industry life cycle }\end{array}$ & $\begin{array}{l}\text { Technology; discontinu- } \\
\text { ity; dominant design; era } \\
\text { of ferment vs. incremen- } \\
\text { tal change }\end{array}$ & $\begin{array}{l}\text { Actors, networks, } \\
\text { institutions, technology; } \\
\text { TIS functions; policies }\end{array}$ \\
\hline $\begin{array}{l}\text { Key } \\
\text { mechanisms }\end{array}$ & $\begin{array}{l}\text { Economies of scale in } \\
\text { R\&D; shift from product } \\
\text { to process innovation }\end{array}$ & $\begin{array}{l}\text { Emergence of dominant } \\
\text { design (including } \\
\text { struggles over d. design) }\end{array}$ & $\begin{array}{l}\text { Interaction of TIS } \\
\text { elements; positive } \\
\text { feedback effects }\end{array}$ \\
\hline Actors & $\begin{array}{l}\text { Firms in the same } \\
\text { market }\end{array}$ & $\begin{array}{l}\text { Firms in the same } \\
\text { market and suppliers, } \\
\text { customers }\end{array}$ & $\begin{array}{l}\text { Firms, associations, } \\
\text { NGOs, policy makers, } \\
\text { consumers }\end{array}$ \\
\hline $\begin{array}{l}\text { Tends to } \\
\text { miss }\end{array}$ & $\begin{array}{l}\text { Institutions, contexts, } \\
\text { inter-industry dynamics }\end{array}$ & Institutions, context & $\begin{array}{l}\text { Interaction of different } \\
\text { technologies }\end{array}$ \\
\hline
\end{tabular}

At the same time, there are several arguments why it seems advisable to use the TIS approach in the context of sustainability transitions, instead of working with and adapting the existing life cycle approaches (Table 1). First, the TIS framework poses equal explanatory weight on actors and institutions. Institutional change plays much less of a role in ILC and TLC approaches, while it is central in sustainability transition studies. Second, the TIS framework takes particular interest in the role of public policies, which are again central when addressing technology change that is associated with sustainability targets. In fact, the TIS approach is explicitly targeting policy makers (rather than managers). Related to that, it is the overarching interest in sustainability at a global level (rather than e.g. economic performance at the national or firm level) that drives recent TIS research. Moreover, the TIS framework emphasizes social processes, including collaboration among actors or coordination of actors by informal institutions (e.g. shared visions). Studies have demonstrated the relevance of such mechanisms in the context of sustainability transitions (Geels et al., 2016b; Wirth et al., 2013).

Concluding this section, it is important to note that there are sufficient overlaps between a TIS perspective and ILC/TLC approaches that justify building on the 
insights of these two strands of literature. This is covered in section 4. Before that, however, it is necessary to introduce the main building blocks of a TIS life cycle perspective.

\section{Building a TIS life cycle framework}

This section introduces and connects three building blocks to study the TIS life cycle. These include i) TIS and context as the two core components, ii) a set of analytical dimensions to distinguish different phases of TIS development, and iii) a transformational perspective that captures the development of the TIS over time (Figure 1). The framework builds primarily on the existing TIS literature, including recent propositions of how to conceptualize the TIS context, as well as institutional dynamics in the TIS context (Bergek et al., 2015; Markard et al., 2016). It also includes parameters such as size, entries/exits, and technology performance, which are key in ILC and TLC literatures.

The suggestions below should be read as a first proposition of how to conceptualize a TIS life cycle and what dimensions, elements and processes to pay attention to. For example, one aspect that is currently missing are the TIS functions (Bergek et al., 2008a) and how they change as a TIS grows, matures and declines. As a consequence, further conceptual refinement will be required, e.g. as we gather experiences from empirical applications.

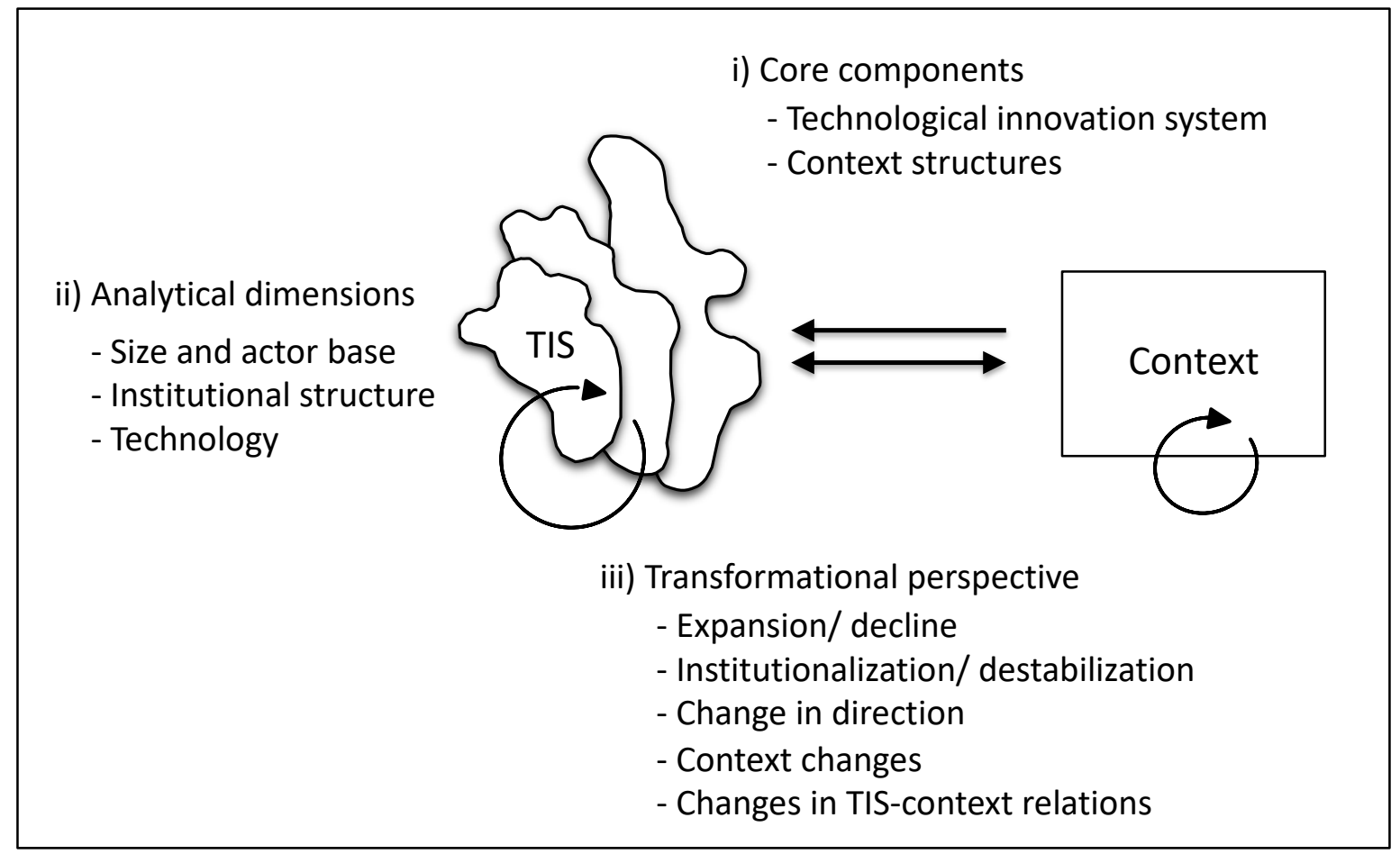

Figure 1: Conceptual framework

The two core components, TIS and context, have been introduced in section 2.1 and don't need to be repeated here. While the focus and starting point is the TIS, 
context is important as well since it affects the development of the TIS over time, and vice versa. At the same time, context structures also change independently of TIS dynamics (see below). Moreover, context remains an open concept in the sense that it is very much an empirical question, which context elements matter in a specific case and at a specific phase of development. Determination of TIS boundaries and identification of relevant context elements should be done in a careful, iterative analytical process (Bergek et al., 2008a; Markard et al., 2015).

\subsection{Analytical core dimensions}

To distinguish different phases of TIS development I propose working with three dimensions: TIS size and actor base, institutional structure and technology. Actors, institutions and technology are key dimensions that can be directly derived from the TIS framework. Networks (which are also central in the TIS definition) may be analyzed as part of the actor or the institutional dimension, depending on whether their activities (e.g. in terms of system building) or their structures are foregrounded. With size, entries/exits, technology performance and variation all being included as key parameters of ILC/TLC studies.

Size and actor base: Broadly speaking, this dimension captures the degree of activity associated with the focal TIS. This can be research activity, entrepreneurial activity, market transactions etc. It can be measured by indicators such as the size of the actor base, changes in size due to entries and exits, types and roles of actors, size of networks, the number of research projects, publications or patents, or the size of the market (sales figures, production volume, installed capacity).

Institutional structure: This dimension captures the degree of structuration ${ }^{7}$ of a TIS, including different kinds of institutions and their coherence and impact. Structuration may occur through the formation of technology standards, value chains and markets with clearly defined products, or the formalization of interorganizational networks and industry associations. Potential measures may include the types of influential institutions (e.g. cognitive vs. regulative), the degree of coherence and guidance they exert, the existence of shared technology performance metrics, whether value chains are highly differentiated (mature) or not, or the level of sophistication in intermediaries and inter-organizational networks.

Technology performance and variation: This dimension looks into the maturity of the focal technology but also into the direction of technology development. Key

7 TIS scholars often refer to actors, networks and institutions as structural elements, while I regard institutions as the key elements of TIS structure, while actors are the elements that represent agency in the system. 
measures include the level of technology performance (based on established performance metrics, see above), the degree of technological variation and the variety of application contexts. Another aspect is whether performance improves in major steps or incrementally. The emergence of a dominant design can also be captured by this dimension. There are overlaps with the institutional dimension.

In future conceptual development, these dimensions can be changed or expanded, where researchers see fit. A fourth dimension, for example, could cover 'what is going on' in different phases of development in the sense of characteristic TIS processes/functions (cf. section 2.1).

\subsection{Transformational perspective}

In order to conceptualize the life cycle of a TIS, we also need vocabulary to describe transformation, including both TIS and context. In a generic and primarily descriptive way, transformation of a TIS can be tracked through changes in its key dimensions: Changes along the first dimension will be referred to as expansion and decline. ${ }^{8}$ A TIS expands, e.g. as a consequence of actors entering the TIS or more experimentation and R\&D projects being carried out. The opposite development is TIS decline with actors leaving and markets shrinking.

Changes along the second dimension will be referred to as institutionalization and destabilization. Institutionalization means that the institutional and interorganizational structures of a TIS become more coherent, formalized and rigid over time (increase in formal regulations and technical standards, clearly defined actor roles and value-chains). This is typically also associated with a decrease of technological variation (cf. TLC literature). Alternatively, friction between different institutions may occur (within the TIS but also between the TIS and its context), coherence declines and TIS structures break up eventually (destabilization).

Third, there may be changes in technology performance and the direction of development. In the literature reviewed above, scholars have mostly reported performance improvements. It remains to be seen whether, e.g. in the decline phase, performance can also decline. Performance improvements can occur incrementally (mature phase) but also more swiftly or in a stepwise manner (earlier phases). As a result of context developments, we may also see rapid performance improvements as complementary technologies become available for example. A specific example of this is the new generation of electric vehicles made possible, among others, by the advent of a new battery technology.

8 Note that also two phases of development are labeled as expansion and decline (section 5). Even though the wording is the same, the phases capture changes in all of the dimensions. 
Another important transformational aspect is change in the direction of technology development. For example, a technology that was initially developed for a specific application (e.g. batteries for consumer electronics) may later be used for a variety of purposes (e.g. batteries for electric vehicles), eventually spawning new TISs. Such 'branching' is typical for generic or multi-purpose technologies (e.g. smart phones).

In addition to the above, it is also necessary to incorporate changes in context and in the relationship between TIS and context.

Context changes: Transformations in the TIS context can have an impact on the focal TIS. These changes may occur independent of the dynamics of the focal TIS, e.g. in the sense of 'landscape type' developments (Geels and Schot, 2007) that include disruptive events (nuclear accidents, financial crisis, war), major shifts in the price of critical commodities, or technological breakthroughs in adjacent fields. However, context changes can also be a result of developments in the focal TIS (as in the case of competing or complementary technologies). For example, a rapidly expanding TIS requires an increasing inflow of resources, which is why TIS actors try to change existing context structures accordingly. The rapid growth of the TIS for biogas in Germany around 2010 led to major changes in agriculture (context), including a massive increase in the cultivation of energy crops where farmers turned from suppliers of food into suppliers of energy(Markard et al., 2016). If such context changes create resistance and conflict, the TIS may be substantially hampered in its further development (Markard et al., 2016; Wirth and Markard, 2011).

Finally, changes in TIS-context relations are also part of the transformation. This process covers changes in the relationships, or structural couplings (Bergek et al., 2015), between the TIS and its context. It includes both creating and disrupting, or re-configuring relations.

In general, TIS context interaction may be uni- or bidirectional. Unidirectional impact of the context on the TIS is typical for early stages of development when a novel technology is associated with promising applications and/or commonly perceived problems in its context. Biogas technology was initially developed to address central problems of the agriculture sector such as eutrophication (Markard et al., 2016). In the case of bidirectional relationships, TIS and context influence each other. One central example of bidirectional TIS-context interaction is about the focal technology competing with, or complementing, a context technology (Markard and Hoffmann, 2016; Sandén and Hillman, 2011).

It must be noted that the above-mentioned processes affect each other. TIS expansion may go hand in hand with institutionalization, which again has an impact on the direction of development. In a similar vein, changes in directionality have repercussions for the relationships between TIS and context. Finally, changes 
in context structure may have implications for all the other processes. This is what will be discussed in the following two sections.

\section{Different phases of TIS development}

To describe a TIS life cycle I suggest distinguishing four stages of development (see Table 2): a formative phase ("nascent TIS"), a growth phase ("expanding TIS"), a phase of maturity ("mature TIS") and a phase of decline ("declining TIS"). The distinction of a formative and a growth phase follows the existing TIS literature (cf. section 2.1.2). The mature TIS corresponds to the phase of stabilization (ILC) and incremental changes (TLC). Accordingly, many of the phase-specific characteristics in the table are taken from the existing life cycle literatures.

The formative phase is characterized by a small number of actors. Sales are virtually non-existent and there is little growth. Actors mainly focus on research and development, experimentation and prototyping. Vertical integration is high because there are no specialized suppliers or vendors (Musiolik and Markard, 2011). Financial resources very much originate from R\&D funding, often through public agencies. Structuration is low. Technology-specific institutions are primarily informal and cognitive institutions such as collective expectations and frames play a key role (Kaplan and Tripsas, 2008; Konrad et al., 2012). The nascent TIS is also characterized by competing ideas and a large variety of technology designs. Applications are unclear or ill-defined and so are performance parameters. It is highly uncertain which concepts will eventually gain ground and whether there will be profitable applications and customer demand. In the formative phase, the TIS very much depends on context structures (e.g. universities, R\&D programs, existing industries, larger societal trends, sustainability challenges) and tends to adapt to these to create legitimacy. TIS actors form ties with context elements. These can be collaborations as well as cognitive linkages of technology characteristics and societal issues for example.

The growth phase is characterized by high growth and high entry rates. The growth phase may also contain a shakeout with high exit rates. Sales volumes are much higher than in the formative phase but still much below market potential. In this phase, the TIS contains a critical mass of actors in different roles and with an increasing level of specialization. Intermediary actors such as technology-specific associations or standardization committees start to appear. There is strong competition and conflicts may arise regarding which standards are to be implemented. Institutional structuration is higher than in the formative phase with a wide range of technology-specific institutions including formal ones such as interoperability standards, technical norms or safety regulations. Value-chains become established and actors collaborate regularly in formal and informal 
networks (Hellsmark and Jacobsson, 2009; Musiolik et al., this issue). Key performance parameters and technology applications have emerged and are widely accepted. Technology diversity declines and a dominant design may emerge. In the growth phase, the ties between TIS and context multiply. The TIS has an increasing impact on the context and conflicts may arise, as in the case of biogas in agriculture (Markard et al., 2016).

Table 2: $\quad$ Four phases of a TIS life cycle

\begin{tabular}{|c|c|c|c|c|}
\hline & Formative phase & Growth phase & Mature phase & Decline phase \\
\hline $\begin{array}{l}\text { Size } \& \text { actor } \\
\text { base }\end{array}$ & $\begin{array}{l}\text { Sales close to zero; } \\
\text { little growth; small } \\
\text { number of actors; } \\
\text { high degree of } \\
\text { vertical integration; } \\
\text { low entry/exit rates }\end{array}$ & $\begin{array}{l}\text { Sales are moderate at } \\
\text { first but grow rapidly; } \\
\text { medium to large } \\
\text { number of actors in } \\
\text { different roles; specific } \\
\text { associations \& inter- } \\
\text { mediaries emerge; } \\
\text { high entry rates; } \\
\text { strong competition } \\
\text { and struggles over } \\
\text { standards }\end{array}$ & $\begin{array}{l}\text { Sales are high; low } \\
\text { growth; medium to } \\
\text { large number of } \\
\text { actors; high degree of } \\
\text { specialization; low } \\
\text { entry/exit rates; } \\
\text { potentially dominant } \\
\text { players; little conflict }\end{array}$ & $\begin{array}{l}\text { Sales below } \\
\text { maximum and } \\
\text { declining; high } \\
\text { exit rates; } \\
\text { intermediaries } \\
\text { lose influence; } \\
\text { increasing } \\
\text { conflict }\end{array}$ \\
\hline $\begin{array}{l}\text { Institutional } \\
\text { structure \& } \\
\text { networks }\end{array}$ & $\begin{array}{l}\text { Low structuration; } \\
\text { high degree of uncer- } \\
\text { tainty; cognitive } \\
\text { institutions central; } \\
\text { loose networks, } \\
\text { incomplete value } \\
\text { chains }\end{array}$ & $\begin{array}{l}\text { Increasing structure; } \\
\text { markets take shape; } \\
\text { technology-specific } \\
\text { institutions emerge; } \\
\text { increasing } \\
\text { formalization; } \\
\text { collaboration in } \\
\text { networks }\end{array}$ & $\begin{array}{l}\text { High degree of } \\
\text { structuration; } \\
\text { uncertainty low; } \\
\text { established markets, } \\
\text { value chains \& } \\
\text { networks }\end{array}$ & $\begin{array}{l}\text { Structural } \\
\text { destabilization; } \\
\text { norms / designs } \\
\text { questioned; } \\
\text { struggles over } \\
\text { institutions; } \\
\text { networks break } \\
\text { up }\end{array}$ \\
\hline $\begin{array}{l}\text { Technology } \\
\text { performance } \\
\text { \& variation }\end{array}$ & $\begin{array}{l}\text { Performance } \\
\text { parameters unclear; } \\
\text { performance low } \\
\text { compared to exist. } \\
\text { technology; high } \\
\text { degree of variation }\end{array}$ & $\begin{array}{l}\text { Performance } \\
\text { parameters clear; } \\
\text { performance } \\
\text { increasing; variation } \\
\text { decreasing; potential } \\
\text { emergence of } \\
\text { dominant design }\end{array}$ & $\begin{array}{l}\text { Performance } \\
\text { increasing; potential } \\
\text { branching of } \\
\text { technology to new } \\
\text { application contexts }\end{array}$ & $\begin{array}{l}\text { Performance } \\
\text { parameters } \\
\text { potentially } \\
\text { questioned }\end{array}$ \\
\hline $\begin{array}{l}\text { Context \& } \\
\text { TIS-context } \\
\text { relationship }\end{array}$ & $\begin{array}{l}\text { TIS depends on } \\
\text { context and adapts } \\
\text { to it; first ties emerge }\end{array}$ & $\begin{array}{l}\text { Ties to context } \\
\text { multiply and } \\
\text { formalize; TIS has } \\
\text { increasing impact on } \\
\text { context; potential } \\
\text { conflicts arise; co- } \\
\text { dependence }\end{array}$ & $\begin{array}{l}\text { High number of close } \\
\text { ties; interaction of } \\
\text { TIS and context; co- } \\
\text { dependence }\end{array}$ & $\begin{array}{l}\text { Ties break up; } \\
\text { dependent } \\
\text { context struc- } \\
\text { tures decline as } \\
\text { well }\end{array}$ \\
\hline
\end{tabular}


The mature phase is characterized by high sales and low growth rates. In this phase the TIS is very stable with low numbers of firm entries and exits. The actor base is characterized by a high degree of specialization and many organizations providing services and complementary products for the focal technology. Large firms might dominate the TIS. In the mature phase, the degree of structuration and institutional stability is high. Products and applications are clearly defined. The technology is not just widely known but even taken for granted. Markets, value chains and inter-firm networks are well established and stable. Technology performance is high but it might still be increasing. The technology might branch of into new applications or fields. There is a high number and variety of close ties between the TIS and the supplier industries, users and infrastructures in its context. TIS and context elements interact and are co-dependent. Due to the high degree of structuration and the close ties with context structures, a mature TIS develops in a path-dependent way and is rather resistant to change. ${ }^{9}$

In the decline phase sales are falling and more and more actors leave the TIS. Intermediaries lose their relevance and established value-chains, and networks break apart. TIS actors are confronted with negative visions on the future of the technology and a destabilization of technology-specific institutional structures. Struggles among actors increase compared to the mature phase. Technology designs and performance parameters may be questioned and defensive actions might be taken, e.g. through political lobbying (Geels and Penna, 2015; Lauber and Jacobsson, 2016). The decline of the focal TIS also affects the context. Finally, established ties break up and complementary industries may decline as well in response.

Note that these are descriptions assume ideal conditions, which may not hold for every TIS. There may be rapidly growing technological innovation systems, in which there are still competing designs (Photovoltaics: crystalline and thin-film cells; wind energy: turbines with and without a gearbox). Also, there may be technologies that still see major improvements or leaps in performance even though they have been in the market for decades (Andersen and Markard, 2017). In fact, we can expect similar exceptions as the ones discussed in the ILC literature (cf. section 2.2).

Moreover, having this set of phases defined does not imply that every TIS will pass through all of them. For example, a TIS may never develop beyond the first, formative phase. This happened, in the case of biomass digestion and also to some extent to wind power in the Netherlands (Bergek and Jacobsson, 2003; Negro et al., 2007). There are also cases in which a TIS has progressed into a growth phase

9 A mature TIS might exhibit a rigidity that is similar to that of socio-technical regimes (Fuenfschilling and Truffer, 2014). 
and was confronted with major resistances and setbacks, exactly because it was expanding rapidly (Jacobsson, 2008; Markard et al., 2016).

Finally, it is important to interpret the above phase descriptions as mid-phase differences, i.e. when a TIS is in the middle of one phase there should be major differences compared to when it was in the middle of an earlier phase. The transitions between phases may be rather smooth, which is why it is challenging to define clear-cut thresholds to identify the end of one phase and the beginning of the next (Bento and Wilson, 2016).

\section{TIS life cycle: changing interactions with context structures}

A TIS may subsequently pass through all four stages of development in the sense of a life cycle. This includes the formation of a novel technology, followed by institutionalization and strong growth, subsequent maturation followed by destabilization, decline and eventual extinction ${ }^{10}$. This section describes the interaction of TIS and context over the course of an ideal-type TIS life cycle. Note that a completion of a TIS life cycle may be (an essential) part of a larger sociotechnical transition. I will come back to this in the discussion.

\subsection{TIS formation and expansion}

Formative phase: In this phase, the TIS very much depends on context structures. The relationships are mostly unidirectional, with context elements affecting the TIS but not vice versa (Figure 2a). The context of a TIS provides potential actors, resources and also guidance for the TIS but it may also constrain TIS development (Bergek et al., 2015). As a consequence, TIS actors actively manage the TIS-context relationships and adapt to the current context, thereby creating legitimacy (Markard et al., 2016). One example is the framing of the novel technology, e.g. in light of major problems in adjacent sectors (Bergek et al., 2008b; Binz et al., 2016; Rosenbloom et al., 2016). Through framing, cognitive relationships are created between the focal technology and the context, which is part of the (early) institutionalization process (Markard et al., 2016).

Cognitive ties are not the only relationships that emerge in the formative phase between TIS and context elements. Others include collaborative ties (e.g. between TIS actors and universities) to support knowledge development or financial ties that provide risk capital or public funding for pilot projects. The latter contribute to resource mobilization, which is one of the key TIS functions.

10 In the sense that a technology is not produced and hardly applied anymore and that its market has become marginal as in the case of VCRs or analog cameras. 
Creating such linkages with the context is not just relevant for TIS expansion but also for the direction of technology development. For example, if a novel technology is framed as the solution to specific context problems, it will later also be assessed as to whether it delivers in this regard (Binz et al., 2016; Rosenbloom et al., 2016). Similarly, if a novel technology receives funds from specific research programs or resources from specific firms, it is likely that the technology will be designed in a way as to fulfill the interests of these resource providers.

The effects of TIS-context linkages on direction, however, do not imply that there is already a clear guidance on the overall direction of technology development in this early phase. On the contrary, actors will pursue different ideas of what the technology could become and how it may be applied. As a result, they create different linkages, eventually drawing the TIS into different, and possibly even competing directions.

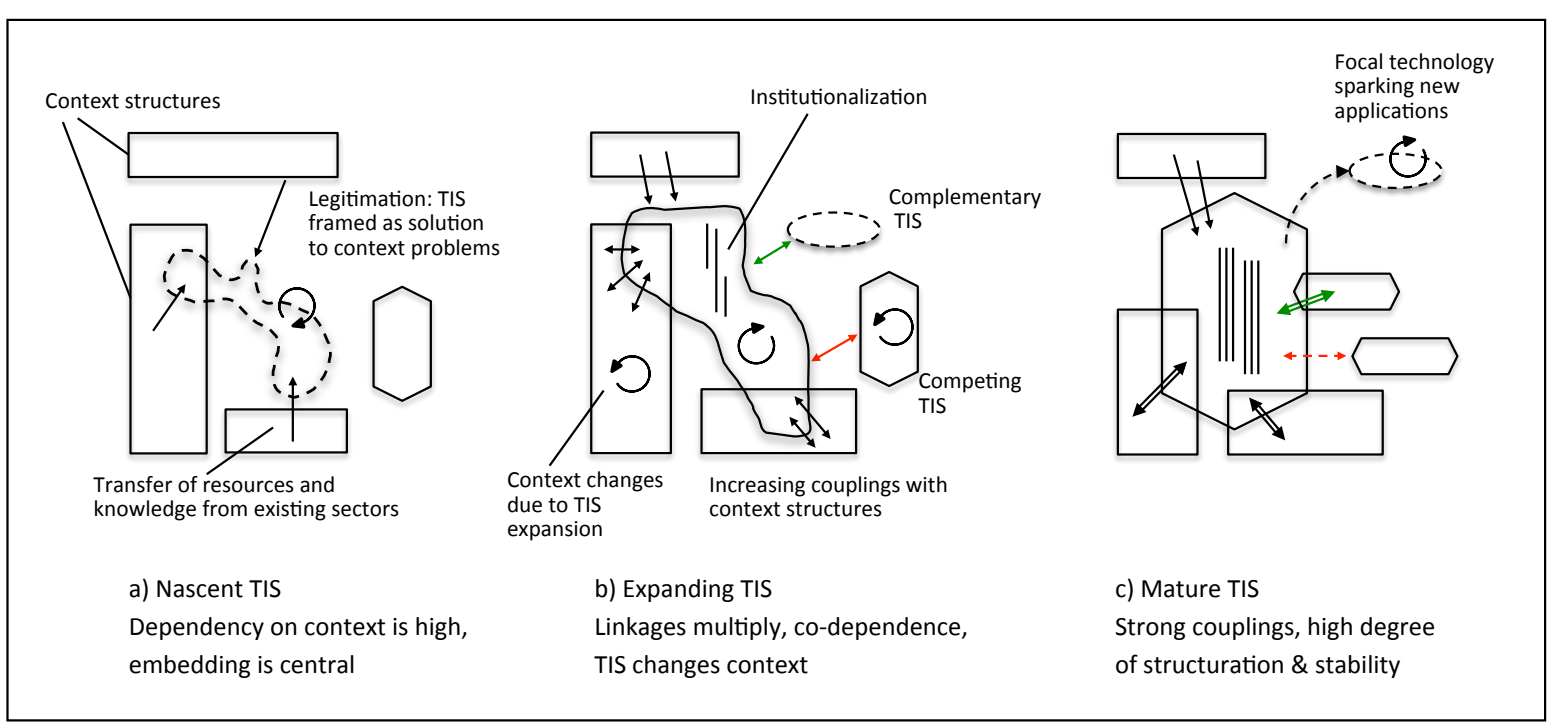

\section{Figure 2: TIS-context interaction during TIS expansion}

Growth phase: In this phase, the TIS is taking shape, i.e. technology-specific institutional structures such as technology standards become increasingly influential. Markets and value chains emerge and a dominant design may form and provide guidance. At the same time, the linkages with the context multiply (Figure 2b, black double-sided arrows). Producer-supplier relationships, for example, connect the emerging TIS to various sectors as well as a complementary TIS (green arrow). In the process of market formation, ties to customers (and application sectors) are also established.

TIS-context relations do not just increase in number but some also become bidirectional (double-sided arrows): As the focal TIS grows, it affects more and more parts of the context, while at the same time also remaining dependent on the context. The TIS-context relationships, in other words, shift from unilateral dependence to multilateral interdependencies. TIS-context relations can be complementary as well as competitive. In the case of a competing technology in 
the TIS context, for example, we can expect that competition is most intense in the growth phase of the focal technology.

\subsection{Maturation and decline}

Mature phase: A mature TIS is characterized by a high degree of institutionalization (vertical lines, Figure 2c). It is highly interrelated with the context through a broad variety of relationships (arrows with double lines). Both TIS-specific structures as well as external relationships are very stable, thereby generating a high degree of inertia. Technology development tends to be incremental and path-dependent.

Like in the growth phase TIS-context interdependence is bi-directional: Some parts of the context (e.g. certain regions, or specific supplier industries) may very much depend on what is going on in the focal TIS. While it is assumed that no major changes occur in the mature stage, some changes happen nonetheless. Given the several interrelations of a focal TIS with various context structures, which are again linked to other systems, there is a good chance of repercussions taking place with the focal TIS. We can also expect incremental performance improvements in this phase. As a consequence, the focal technology might spread to new application contexts or customer segments, as in the case of smart phones (see below).

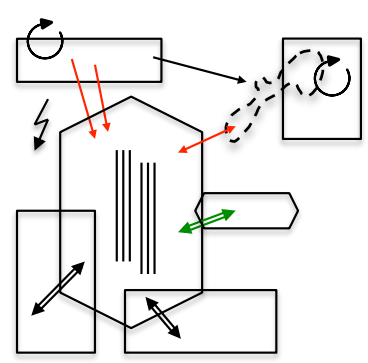

a) Mature TIS under pressure Conflicts, misalignments \& new competition, e.g. due to changes in context

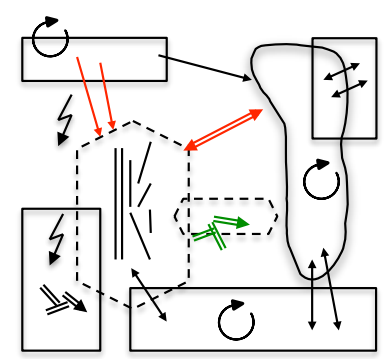

b) Declining TIS Relationships break up, TIS destabilizes, conflicts multiply

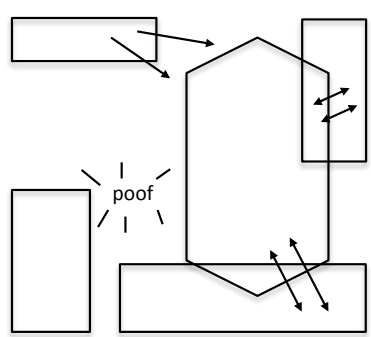

c) TIS vanished, substituted by a different one

\section{Figure 3: TIS-context interaction during TIS decline}

Decline phase: TIS decline may be initiated by major shocks and/ or novel competing technologies (Figure 3a, red arrows, flashes). In either case the context is central, and it is assumed that decline is often driven by exogenous developments. However, it may also be the case that novel competing technologies (red arrows) are developed by incumbent actors (Berggren et al., 2015), i.e. from within the TIS. TIS actors may seize opportunities to enter a new TIS and develop 
new business opportunities, thereby contributing to the decline of the focal technology. ${ }^{11}$

Context changes create misalignment and conflict, thus exerting pressure on the TIS. A consequence is destabilization, where technology specific institutional structures such as regulatory support or collective beliefs in future prospects are weakened (vertical lines disassembled). Additionally, resource flows may decrease, as a consequence of a novel technology taking over market shares or firms shifting $R \& D$ resources to the novel TIS for example (Figure $3 b$ ). As actors leave the TIS and sales go down, the focal TIS declines. TIS-context relationships break-up, lose their importance or might turn from positive to negative. Complementary technologies, or industries, may either destabilize with the TIS, or support the competing technology, as in the case of smart phones.

As the TIS declines, further institutional misalignment might occur. This increases the pressure even more and actors exit in greater numbers. In this phase, there might be vicious circles and negative feedback loops at work that are very similar but opposite to the ones that propelled the growth phase. Context structures will change accordingly, e.g. as they take over the market that has been covered by the TIS before. At the end of the life cycle (Figure 3c), the focal technology may either cease to exist as in the case of video recorders, or it may survive in some small remaining niche application (e.g. vinyl discs).

This sequence of phases is just one possible pattern for TIS development, and alternative paths of transformation are possible. For example, a novel technology may die early, with the associated TIS declining without having ever reached the emerging or mature state. Decline may also be delayed (sailing ship effect) or even interrupted by some form of re-configuration or re-vitalization (e.g. as a consequence of new technological advances in an adjacent field).

\section{Examples of TIS dynamics and decline}

This section presents three illustrative examples of TIS dynamics in home entertainment, mobile communication and lighting. The main criteria for choosing them was that they include decline and that decline unfolded globally, not just regionally. The particular interest in decline is motivated by its relevance from a sustainability transitions perspective and the fact that the existing TIS and life

11 From a TIS life cycle perspective, such a strategic shift by a TIS actor can be interpreted as devoting less resources (and eventually leaving) the old TIS, while entering a new TIS. 
cycle literature has not studied decline in detail (cf. section 2).12 The examples differ with regard to the relevance of public policy involvement, which is particularly important in the lighting example, where dedicated phase-out policies accelerated the decline. In the mobile communication example, policy and regulation played a significant role in standardization during the formative phase. In home entertainment, policies played no decisive role. This is a particularly interesting case nonetheless because it includes one full TIS life cycle. All other decline processes presented below are still ongoing.

\subsection{Home entertainment}

The field of video home entertainment has seen two major shifts in technology since the 1990s: from videocassettes to DVDs and from DVDs to online streaming (Figure 5). The TIS on VCR technology (including video recorders and videocassettes as core products) emerged in the early 1970s, and expanded rapidly on a global scale in the 80 s before starting to decline in the $90 \mathrm{~s}$. The formative years of TIS development were characterized, among others, by a major battle over technology standards, which was won by the VHS standard around 1980 (Cusumano et al., 1992). VCR technology not only created new markets in consumer electronics (VCR development and production) and entertainment (movies $\&$ shows on videocassettes) but also initiated complementary services such as video rentals (Figure $4 \mathrm{a}$, green arrows).

In 1997, the DVD technology emerged with the promise of superior performance in terms of video and audio quality, as well as search functions (Jarvenpaa and Makinen, 2008). Three years later, the DVD player was labelled the fastest selling consumer electronics product in history. ${ }^{13}$ As a result, DVDs quickly supplanted videocassettes in just a few years (Figure 5). From a TIS life cycle perspective, this development can be interpreted as a novel TIS emerging and directly competing (red arrow) with the existing one. An important aspect for the development of the DVD TIS was that it could build on existing organizations, as well as existing competences and structures in the video rental business and the entertainment industry (Figure 4b). Moreover, most VCR manufacturers (e.g. JVC, Sony) also

12 This is not to say that there are no studies on decline at all. On the contrary, many scholars have studied industry decline, see e.g. Lamberg et al. (2017) for a review. However, most industry decline studies have a regional focus, i.e. they study the downturn of a particular industry in a particular region or country. Examples include the decline of the British coal or textile industry (Lazonick, 1983; Turnheim and Geels, 2012).

13 https://www.digitalbroadcasting.com/doc/its-official-dvd-now-fastest-consumerelectro-0001, accessed Sept-12, 2017 
became central players in the DVD TIS, so there was not a major disruption for incumbents. Despite the successful expansion and maturation of the DVD TIS, it was not until 2016 when a Japanese manufacturer announced the end of VCR production. ${ }^{14}$ So, the entire VCR life cycle took about 45 years, including almost 20 years of decline.

Like videocassettes, DVDs also faced competition: first by Blue-Ray and highdefinition DVD formats and later by video streaming. It was especially the latter that meant a second major technology shift for home entertainment. Digital technology and the increasing availability of personal computers and high-speed Internet made online video streaming a viable and convenient alternative to DVDs and recorders. From a TIS perspective, the streaming TIS builds on several complementary TISs, industries and infrastructures (Figure 4c). In the U.S., spending on DVDs \& HD-DVDs peaked around 2006, about 10 years after its introduction. Afterwards, DVD sales declined rapidly and were overcome by sales in online video streaming around 2016 (Figure 5).

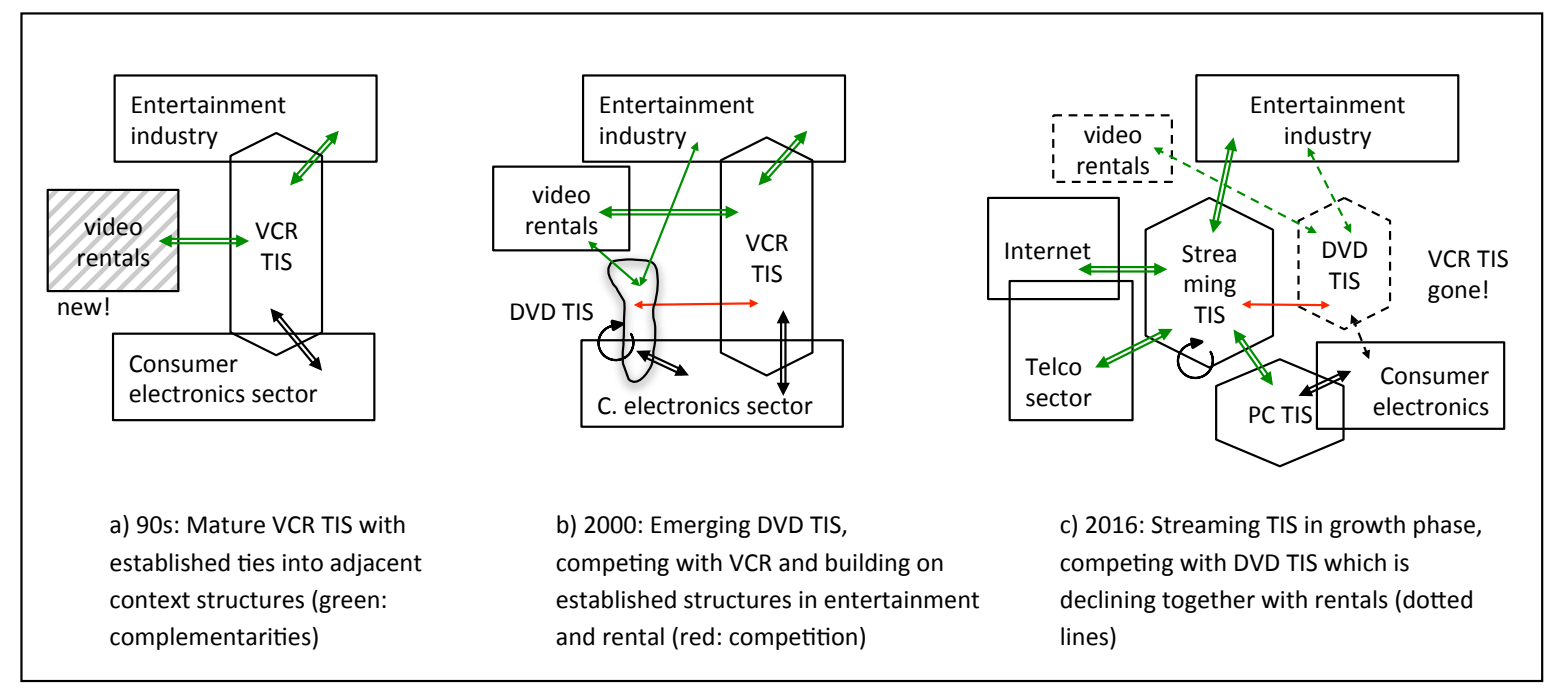

Figure 4: Technology shifts in home entertainment from a TIS life cycle perspective

The example of home entertainment is interesting for several reasons. First, it highlights the key role of complementary technologies and services (recorders and videocassettes, rental services, high-speed Internet, computers etc.). This again underlines the relevance of context developments for the study of TIS life cycles. Second, while it demonstrates how quickly key technologies can lose their dominant position, it also shows how long a phase of global decline can actually last. Third, the example also illustrates that the consequences of technology shifts

14 https://www.forbes.com/sites/brittanyhodak/2016/07/23/rip-vhs-worlds-last-vcrto-be-made-this-month/\#74b790c623da, accessed Sept-12, 2017 
can be very different for incumbent firms. While the shift from VHS to DVD left the video rental business intact without significantly affecting producers of consumer electronics, the second shift was more disruptive (dashed lines in Figure 4c depict weakened ties and industries) for the video rental industry ${ }^{15}$, firms in consumer electronics, and even the entertainment industry.

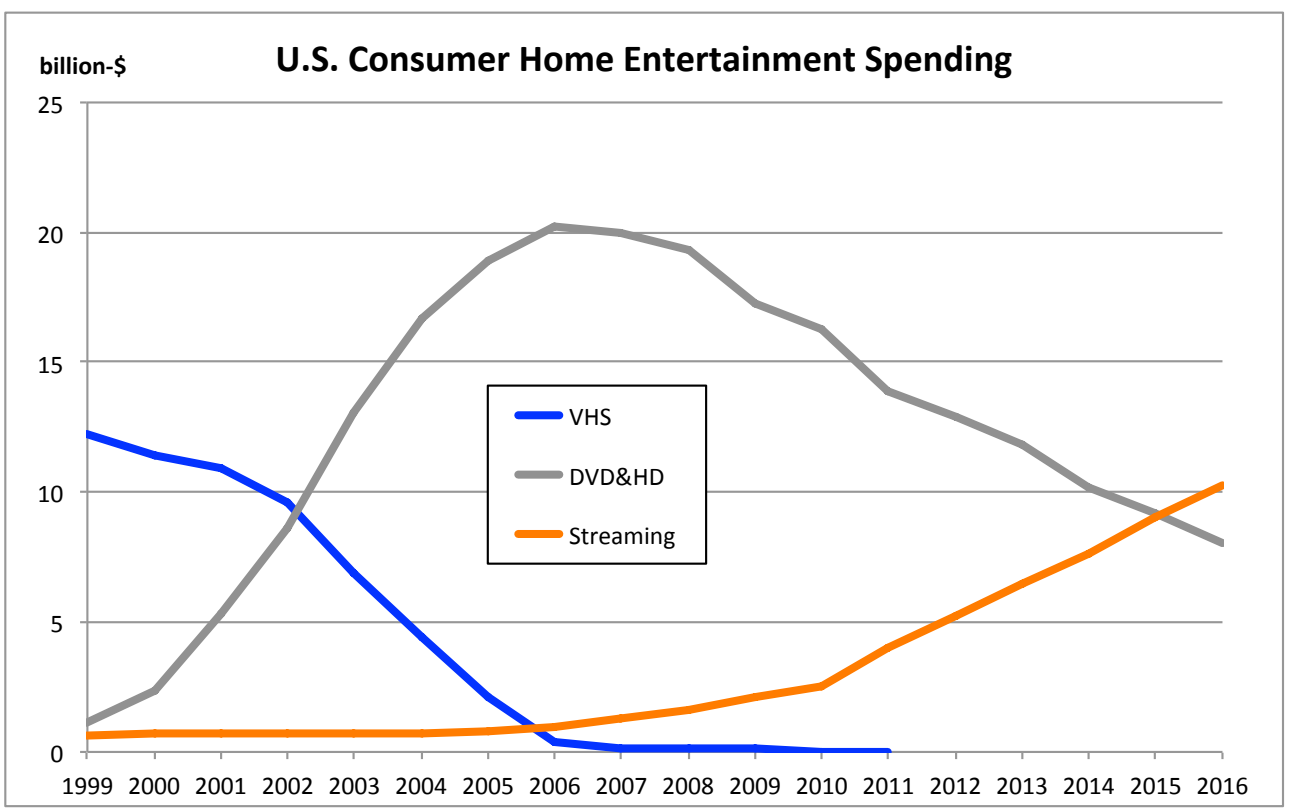

Source: The Digital Entertainment Group, diverse reports. Figures include movie rentals.

Figure 5: Competition of different technologies in video home entertainment

\subsection{Mobile communication}

The field of mobile communication has witnessed a major technology shift from mobile phones to smart phones (Figure 6). Despite much earlier experiments, the mobile phone TIS started to develop when Motorola presented its first prototype in 1973. ${ }^{16}$ However, it suffered from the dilemma that the phones required a complementary network infrastructure, and vice versa. The build-up of the infrastructure was again hampered by the challenge that a common standard was needed, not just at a national level but also ideally at an international level (Funk and Methe, 2001). Consequently, the TIS did not take off until after a second generation of mobile phones and digital transmission technologies, including the GSM standard, emerged in the 1990s. Again, battles over technology standards played a key role in the formative phase (ibid.).

15 Only a few video rental firms, one of them being Netflix, have survived the breakthrough of online streaming.

16 See Agar (2013) for an encompassing account of the history of mobile phone technology. 
Around the year 2000, the first smart phones appeared on the market. They diffused successfully first in Japan and then in North-America (BlackBerry). Widespread global diffusion of smart phones kicked in after 2009 associated with the launch of the Apple's iPhone in 2007. The primary conditions for the swift formation and growth of the smart phone TIS were the following: it could seamlessly build on and use the existing network infrastructure (given the leap in data transmission capacity from the $3 \mathrm{G}$ standard onwards), a broad range of established services (e.g. those provided by telco operators) and users who were enthusiastic and already familiar with the predecessor technology. So, this is another case of a competing TIS benefiting from essential complementary structures created during the development of the prior TIS.

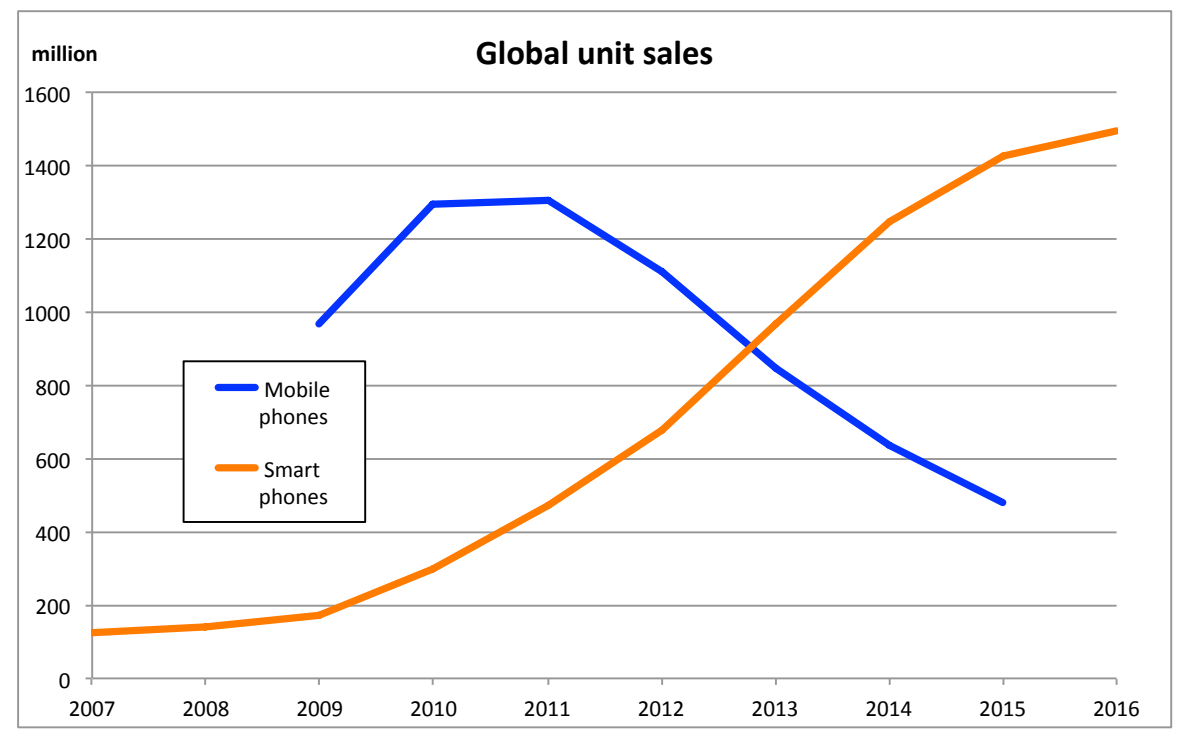

Source: Statista.com

Figure 6: Competition of mobile feature phones and smart phones

Smart phones technology is fundamentally different from mobile phone technology as it combines a broad variety of functional features beyond telecommunication (improved screen display, cameras, sensors etc.) and can use a broad range of third-party software applications. In other words, the smart phone TIS provides a platform technology that enables an almost infinite number of applications (Cusumano, 2010). As a consequence, it will have a pervasive impact on its broader context.

The shift from mobile to smart phone technology was a disruption for most manufacturers. Leading mobile phone producers such as Nokia, Motorola and Ericsson lost their market position or went bankrupt, while other firms such as Apple (and Huawei to a lesser extent) entered the market and acquired a central role (e.g. Vuori and Huy, 2016). Samsung is one of the few players being successful in both mobile and smart phone TIS. 
This example has several parallels with the first one. Again, complementary structures (here: services, competences, standards, consumer expectations and network infrastructure) were highly relevant for TIS formation. Again, the successor TIS could build on many of the existing structures and therefore grow much quicker than the first TIS. ${ }^{17}$ We can assume that these dynamics also accelerated the decline of the prior TIS. A novelty in the case of the smart phone TIS is that it generates a platform technology, which multiplies the number of potential applications and has significant impacts on many other industries in the wider context such as banking, gaming, social media etc. Another interesting feature of this example is that the novel technology could build on infrastructures, user practices and services that were already in place from its predecessor.

\subsection{Lighting}

The field of lighting has witnessed two major technology shifts in the past 30 years. Throughout most of the $20^{\text {th }}$ century, incandescent light bulbs (ILB) were the dominant technology, especially in residential applications. Since the oil crises in the 1970s, the ILB TIS was confronted with pressure from environmental initiatives and public campaigns to reduce energy consumption. In the 1980s, compact fluorescent lamps (CFL technology) were developed as an alternative that was more expensive but about 4-5 times more energy efficient and had a much longer lifetime. The new CFL TIS included most incumbent ILB manufacturers and technology diffusion was supported in many places by public and private programs (labels, campaigns, subsidies). Even though the CFL technology improved over the years, substitution of ILBs was slow and CFLs peaked at a global market share of around 20-25\% (Vahl et al., 2013).

Around 2009, the LED technology, a technology with its origins in the semiconductor industry, had improved in such a way that it could be adapted for lighting purposes (i.e. an example of a technology spawning new applications in its mature phase). This triggered the formation of the LED TIS. When first introduced, LED lighting was more efficient and durable than any other technology. As it became cheaper than e.g. CFL technology, it diffused very rapidly in many countries and regions, which is why commentators meanwhile also speak of an "LED lighting revolution". ${ }^{18}$ It is expected that LED technology will dominate the lighting market in the upcoming years (McKinsey, 2012).

17 Parasitic relationship, cf. Sanden and Hillman (2011).

18 https://thinkprogress.org/5-charts-that-illustrate-the-remarkable-led-lightingrevolution-83ecb6c1f472/, accessed Sept-13, 2017 
A particular characteristic of the TIS competition and succession in lighting is that, in many countries, incandescent light bulbs were banned by regulation (Howarth and Rosenow, 2014; Stegmaier et al., 2012). First bans were issued in Brazil and Venezuela in 2005 and many countries followed suit, including the European Union which gradually phased-out the light bulbs starting in 2009. The primary reason for these strict policies was the ambition to reduce energy consumption. Interestingly, major industry players such as Philips or Osram were in favor of such bans, and at the same time were keen to influence quality and measurement standards for LED technology to benefit from the development (Smink et al., 2015).

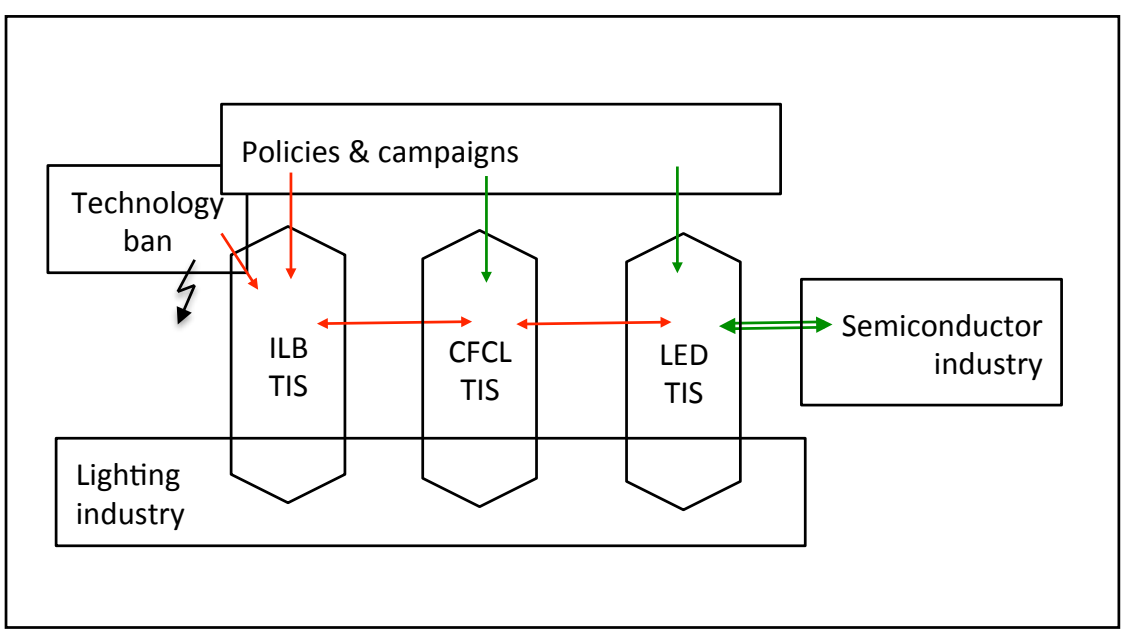

\section{Figure 7: Multiple competing TIS in lighting and policy effects}

This example is interesting for two reasons. First, all technological alternatives were supported, and partly driven, by incumbent manufacturers. Second, regulation and sustainability issues played a central role, first in the form of 'softer' instruments such as labels and subsidies, and later even through technology bans. In other words, TIS decline has been explicitly accelerated by public policies. As similar approaches can be observed in some places for coal-fired and nuclear power generation, this example is particularly relevant from a sustainability transitions perspective.

\subsection{Insights for TIS life cycle studies}

The above examples have illustrated the complexity of technology and industry dynamics and some of the many technological, organizational and institutional aspects that come into play. In a next step, complete case studies will be needed to fully apply and test the usefulness of the life cycle perspective. From the above examples, we can already learn some interesting lessons.

First, even if we focus on a particular technology, we might be confronted with a development, in which complementary and competing technological innovation systems as well as adjacent industries and sectors closely interact. This is why it 
is vital to not only look at a focal technology but to also take relevant context structures into account when studying long-term TIS dynamics (Bergek et al., 2015).

A variation of this argument is that a TIS can have structural couplings with industries or other sectors (Stephan et al., 2017). These include 'vertical' industries in different parts of the value chain (e.g. the semiconductor industry in the LED case) as well as 'horizontal' (service) industries that complement the focal product (network operators, software developers, repair and rental services etc.).

Second, (global) technology decline often goes hand in hand with the diffusion of a technological alternative that targets a similar market or fulfills a similar function. This is the 'classic' substitution pattern we also know from historic studies of socio-technical transitions (Geels, 2002; Geels, 2006). At the same time, however, specific industries and the associated business models may also vanish completely as in the case of video rentals.

A third element of a TIS life cycle is that the focal TIS may spawn entirely new businesses and services which are complementary to the focal technology (e.g. video rentals, programming of Apps). While many of these new industries may strongly depend on the focal technology as they generate complementary products or services, some may also survive the decline of the focal technology and complement its successor. A related phenomenon are wider effects on the TIS context with are particularly pervasive in the case of multi-purpose or generic technologies such as the internet, mobile communication or IT more generally. In such situations, the emergence and maturation of a new TIS may affect many other industries (both existing and newly emerging) in the broader context.

A fourth insight is about organizations: Some players survive technology decline while others do not. So there seems to be a general effect of decline, which is negative for the firms in the associated industries with some exceptions. In the above examples, some incumbents survived major technology shifts (e.g. Samsung, Sony, JVC) and even the decline of an entire industry (e.g. Netflix). In fact, incumbents might even benefit from the new technology - think of mobile communication service providers or lighting manufacturers. As a consequence, they may turn out as proponents rather than opponents of technological change (Berggren et al., 2015). This certainly asks for a qualification of one of the central assumptions in transition studies, which depicts the transition as a battle between newcomers and incumbents (Penna and Geels, 2012; Smink et al., 2015; Wesseling et al., 2014).

Finally, every life cycle approach has to deal with variation and deviations from the 'typical'. Explanations for variation can be sought, among others, by looking into different types of technologies. Tushman and Rosenkopf (1992) have suggested distinguishing the complexity of products (steel vs. containers vs. televisions vs. 
railroad systems) in order to understand differences in technology development. This is similar to the proposition to distinguish mass-produced goods from complex products (Huenteler et al., 2016). The above example of smart phones seems to suggest that also the applicability of the technology matters in the sense of single, multi-purpose, and generic technologies.

\section{Discussion}

This contribution represents a first step in the endeavor to develop a TIS based framework for the study of socio-technical transitions. Next, I discuss particularities of the approach as well as shortcomings, which will have to be addressed by future research.

Breaking up with earlier TIS conceptualizations: The life cycle perspective breaks up with some established views in the TIS literature. The idea that a TIS changes over time in a way that reflects the development of the focal technology is new. While it has been argued before that a TIS has a beginning (Markard and Truffer, 2008), there has been hardly any debate about the ending. In this paper, the ending is connected to the focal technology vanishing. This is an important issue that challenges the view that a 'healthy' TIS can constantly innovate thereby preventing extinction. Of course, innovation in relation to the existing focal technology is possible ('sailing ship effect'). The examples have also shown that firms may well survive technology decline and be successful with the new technology. However, there is also the possibility of the focal technology, and the associated TIS, not surviving. I argue that this course of development is particularly relevant from a sustainability transitions perspective, which is not only about the emergence of more sustainable alternatives but also about the decline of unsustainable technologies.

Another issue is that the life cycle perspective requires the TIS to include both production and innovation, i.e. all elements that support the focal technology regardless of whether they are primarily concerned with production, service provision or innovation. This is a break with the earlier suggestion of Markard and Truffer (2008) who concentrated on the innovation part and therefore proposed a different ending of a TIS.

Transformational perspective: The ideas concerning transformational processes in section 3.2 need to be developed further. So far, the perspective is primarily descriptive, and very much based on the main analytical dimensions. An important next step will be to explore and identify key causal processes that 'drive' the development from one phase to another. One such process could build upon the positive feedbacks that are characteristic for the growth phase (or negative feedbacks during decline), while another one could be related to the role of 
legitimacy creation for the direction of technology development (Bergek et al., 2008b; Markard et al., 2016). Contingent events and external developments in the context also certainly have causal effects on the TIS life cycle (Bergek et al., 2015).

Clarify relationship of TIS functions and transformational processes: The processes for transformation will certainly overlap with the TIS functions that are used prominently in current TIS studies. For example resource mobilization is closely related to building ties between TIS and context, thereby being affected by contextual institutional embedding (cf. Hoogma et al., 2002) and legitimation (Bergek et al., 2008b; Binz et al., 2016). In a similar vein, market formation and the direction of search both overlap with what has been referred to as institutionalization (section 3.2). Future conceptual work should address these relationships systematically.

How to deal with TIS functions and decline: TIS analysis, conducted with the seven functions, is often guided by the idea that the overall purpose is to maintain and improve the TIS and its core technology, and not to abandon it. This creates a fundamental conflict with decline - especially when the decline is not just the result of a failure of TIS functioning, but of purposeful policymaking (Kivimaa and Kern, 2016). Working with a TIS life cycle approach in the context of sustainability transitions requires a new interpretation of TIS functions that we have yet to develop. Kivimaa and Kern (2016) have suggested functions (or processes) that target regime destabilization; a related idea could be to study (and politically support) processes that contribute to TIS decline.

Normative vs. descriptive perspective: A closely related aspect is whether to take a normative or a descriptive approach. For TIS formation and growth, TIS scholars have adopted the perspective of actors who have an interest to support and strengthen the focal TIS. In other words, the underlying assumption has been that there is a widely shared interest to establish the focal technology. This assumption can been questioned, of course (Bening et al., 2015; Markard et al., 2015). At the same time, this assumption is central when using the TIS in the context of sustainability transitions, where policy making is based upon discerning wanted from unwanted technologies in society, like in the case of the light bulb.

So what policy perspective should we take with regard to a mature or declining TIS? Should a TIS performance assessment then follow the intention of making the TIS strong again and to maintain or improve the focal technology - a perspective often taken in the literature on industry decline (Lamberg et al., 2017)? Or should the assessment be guided by the goal of accelerating decline, and give way for emerging and possibly more sustainable alternatives (Kivimaa and Kern, 2016)? From a sustainability transitions perspective, I would argue that as soon as societies select preferred technologies, they also deselect others - whether this is implicit or explicit, i.e. when phase-out policies are formulated. In this context, the 
TIS life cycle perspective can be useful to study processes of decline and to inform policy making directed at accelerating the phase-out of unwanted technologies.

The spatial dimension: TIS scholars have also began to grasp the complexity of the spatial dynamics of technology development (Binz et al., 2014; Gosens et al., 2015). In this paper, I have left the spatial aspects of a TIS life cycle very much aside to minimize the complexity of the study. However, patterns of spatial technology diffusion and maturation (Dewald and Truffer, 2012), creation of international value chains (Bento and Fontes, 2015), regional decline vs. global expansion, or the role of spatial relationships and local differences in contextual embedding (Bergek et al., 2015) are certainly important for a more complete understanding of TIS life cycles. As a consequence, the spatial aspects of long-term TIS dynamics are a central piece in the future TIS research agenda.

\section{Conclusion}

The TIS approach is a conceptually strong approach for the study of technology and industry dynamics. In this article, I have introduced and illustrated key elements of a TIS life cycle framework, which can be an important step of conceptual development addressing the next phase of transition, in which novel technologies diffuse widely, while unsustainable technologies decline (Markard, in press). The life cycle approach maintains that TIS structures change as the underlying technology develops and directs attention not only to the early stages of TIS development but also to maturity and decline. The latter are particularly relevant if the TIS framework is to be used in the context of sustainability transitions, in which the phase-out of 'unsustainable' technologies is a central element. In fact, the suggested TIS life cycle approach can be viewed as an important next step towards developing a TIS based transition framework.

A TIS life cycle perspective opens many new doors. These include dedicated studies on technology decline and central mechanisms therein, the specification and empirical investigation of transformational processes (from one phase to another), the complementary interaction of different technologies and industries (Markard and Hoffmann, 2016), and the analysis of spatial and technological differences in the development of TIS over long time spans (Binz et al., 2014; Huenteler et al., 2016).

A potential caveat of working with the TIS approach, however, is that it still has a strong focus on the role of technology in transitions (vis-à-vis other, non-technical changes) and centers around a focal technology. While this focus is certainly helpful to reduce the analytical complexity, there is also a risk to reify the focal technology and to miss out on important and equally sustainable developments in competing fields, or to place the interests of those involved in the focal technology 
over the interests of other actors. Another risk is that the focus on technology dynamics might somewhat conceal the relevance of social, organizational and institutional dynamics, which are closely interrelated with technological changes.

Developing the TIS life cycle perspective further and testing its merits represents a major empirical endeavor. Technology decline, for example, is a process we still know little about. A related issue for further research is maturity and TIS stability. This area of research can certainly benefit from existing studies on socio-technical regimes (Geels, 2002; Raven and Verbong, 2007; Rip and Kemp, 1998), thereby translating the existing insights into the TIS concept.

It must also be noted that life cycle approaches search for commonalities rather than differences. As a consequence, there is a risk of overlooking differences in technology or industry characteristics such as the one between mass-produced products and one-of-a-kind, large-scale projects (Davies, 1997; Huenteler et al., 2016). Further empirical studies may therefore want to focus on this issue and systematically track differences between technologies.

To conclude, a TIS life cycle approach is an important step toward mobilizing the framework's full potential for the purpose of sustainability transition studies.

\section{Acknowledgements}

This article has had a long journey. First ideas were developed in a conference paper in 2013, and different versions were presented at IST conferences in 2013, 2016 and 2018. The article very much benefited from comments I received in these sessions and from the suggestions of three very committed and patient anonymous reviewers. I also thank my colleagues at SusTec/ETH as well as Allan Andersen, Nuno Bento, Amin Dehdarian, Uli Dewald, Marko Hekkert, Jonathan Köhler, Peter Murmann, Rob Raven, Bernhard Truffer and Rainer Walz for their inputs and support.

\section{References}

Agar, J., 2013. Constant touch: A global history of the mobile phone. Icon Books Ltd.

Agarwal, R., Tripsas, M., 2008. Technology and industry evolution. The Handbook of Technology and Innovation Management 1, 1-55.

Andersen, A.D., Markard, J., 2017. Innovating incumbents and technological complementarities: How recent dynamics in the HVDC industry can inform transition theories, TIK Working Papers. University of Oslo, Centre for Technology, Innovation and Culture, Oslo, p. 33.

Anderson, P., Tushman, M.L., 1990. Technological discontinuities and dominant designs: A cyclical model of technological change. Administrative Science Quarterly, 604-633. 
Bening, C.R., Blum, N.U., Schmidt, T.S., 2015. The need to increase the policy relevance of the functional approach to technological innovation systems. Environmental Innovation and Societal Transitions.

Bento, N., Fontes, M., 2015. Spatial diffusion and the formation of a technological innovation system in the receiving country: The case of wind energy in Portugal. Environmental Innovation and Societal Transitions 15, 158-179.

Bento, N., Wilson, C., 2016. Measuring the duration of formative phases for energy technologies. Environmental Innovation and Societal Transitions 21, 95-112.

Bergek, A., Hekkert, M., Jacobsson, S., 2008c. Functions in innovation systems: A framework for analysing energy system dynamics and identifying goals for systembuilding activities by entrepreneurs and policy makers, in: Foxon, T., Köhler, J., Oughton, C. (Eds.), Innovation for a Low Carbon Economy. Edward Elgar.

Bergek, A., Hekkert, M.P., Jacobsson, S., Markard, J., Sanden, B.A., Truffer, B., 2015. Technological innovation systems in contexts: Conceptualizing contextual structures and interaction dynamics. Environmental Innovation and Societal Transitions 16, 51-64.

Bergek, A., Jacobsson, S., 2003. The Emergence of a Growth Industry: A Comparative Analysis of the German, Dutch and Swedish Wind Turbine Industries, in: Metcalfe, J.S., Cantner, U. (Eds.), Change, Transformation and Development. Physica-Verlag (Springer), Heidelberg, pp. 197-228.

Bergek, A., Jacobsson, S., Carlsson, B., Lindmark, S., Rickne, A., 2008a. Analyzing the functional dynamics of technological innovation systems: A scheme of analysis. Research Policy 37, 407-429.

Bergek, A., Jacobsson, S., Sanden, B.A., 2008b. 'Legitimation' and 'Development of external economies': Two key processes in the formation phase of technological innovation systems. Technology Analysis \& Strategic Management 20, 575-592.

Berggren, C., Magnusson, T., Sushandoyo, D., 2015. Transition pathways revisited: Established firms as multi-level actors in the heavy vehicle industry. Research Policy 44, 1017-1028.

Binz, C., Harris-Lovett, S., Kiparskyd, M., Sedlak, D.L., Truffer, B., 2016. The thorny road to technology legitimation - Institutional work for potable water reuse in California. Technological Forecasting and Social Change 103, 249-263.

Binz, C., Truffer, B., 2017. Global Innovation Systems-A conceptual framework for innovation dynamics in transnational contexts. Research Policy 46, 1284-1298.

Binz, C., Truffer, B., Coenen, L., 2014. Why space matters in technological innovation systems - Mapping global knowledge dynamics of membrane bioreactor technology. Research Policy 43, 138-155.

Carlsson, B., 1997. On and off the beaten path: the evolution of four technological systems in Sweden. International Journal of Industrial Organization 15, 775-799.

Carlsson, B., Elg, L., Jacobsson, S., 2010. Reflections on the Co-evolution of Innovation Theory, Policy and Practice: The Emergence of the Swedish Agency for Innovation Systems, in: Smits, R., Kuhlmann, S., Shapira, P. (Eds.), The Theory and Practice of Innovation Policy. Edward Elgar, pp. 145-168.

Carlsson, B., Jacobsson, S., 1994. Technological systems and economic policy: the diffusion of factory automation in Sweden. Research Policy 23, 235-248.

Carlsson, B., Stankiewicz, R., 1991. On the nature, function and composition of technological systems. Evolutionary Economics 1, 93-118.

Cusumano, M., 2010. Technology strategy and management: The evolution of platform thinking. Commun. ACM 53, 32-34. 
Cusumano, M.A., Mylonadis, Y., Rosenbloom, R.S., 1992. Strategic Maneuvering and Mass-Market Dynamics: The Triumph of VHS over Beta. Business History Review 66, 51-94.

Davies, A., 1997. The life cycle of a complex product system. International Journal of Innovation Management 1, 229-256.

Dewald, U., Truffer, B., 2012. The Local Sources of Market Formation: Explaining Regional Growth Differentials in German Photovoltaic Markets. European Planning Studies 20, 397-420.

Funk, J.L., Methe, D.T., 2001. Market- and committee-based mechanisms in the creation and diffusion of global industry standards: the case of mobile communication. Research Policy 30, 589-610.

Geels, F.W., 2002. Technological transitions as evolutionary reconfiguration processes: a multi-level perspective and a case-study. Research Policy 31, 1257-1274.

Geels, F.W., 2006. Co-evolutionary and multi-level dynamics in transitions: The transformation of aviation systems and the shift from propeller to turbojet (19301970). Technovation 26, 999-1016.

Geels, F.W., Berkhout, F., Van Vuuren, D.P., 2016a. Bridging analytical approaches for low-carbon transitions. Nature Climate Change 6, 576-583.

Geels, F.W., Berkhout, F., van Vuuren, D.P., 2016b. Bridging analytical approaches for low-carbon transitions. Nature Climate Change 6, 576.

Geels, F.W., Penna, C.C.R., 2015. Societal problems and industry reorientation: Elaborating the Dialectic Issue LifeCycle (DILC) model and a case study of car safety in the USA (1900-1995). Research Policy 44, 67-82.

Geels, F.W., Schot, J., 2007. Typology of sociotechnical transition pathways. Research Policy 36, 399-417.

Geels, F.W., Sovacool, B.K., Schwanen, T., Sorrell, S., 2017. Sociotechnical transitions for deep decarbonization. Science 357, 1242-1244.

Gort, M., Klepper, S., 1982. Time Paths in the Diffusion of Product Innovations. The Economic Journal 92, 630-653.

Gosens, J., Lu, Y., Coenen, L., 2015. The role of transnational dimensions in emerging economy - 'Technological Innovation Systems' for clean-tech. Journal of Cleaner Production 86, 378-388.

Hekkert, M., Negro, S., 2009. Functions of innovation systems as a framework to understand sustainable technological change: Empirical evidence for earlier claims. Technological Forecasting and Social Change 76, 584-594.

Hekkert, M., Suurs, R.A.A., Negro, S., Kuhlmann, S., Smits, R., 2007. Functions of Innovation Systems: A new approach for analysing technological change. Technological Forecasting and Social Change 74, 413-432.

Hellsmark, H., Jacobsson, S., 2009. Opportunities for and limits to Academics as System builders - The case of realizing the potential of gasified biomass in Austria. Energy Policy 37, 5597-5611.

Hoogma, R., Kemp, R., Schot, J., Truffer, B., 2002. Experimenting for Sustainable Transport. The approach of Strategic Niche Management. Spon Press, London / New York.

Howarth, N.A.A., Rosenow, J., 2014. Banning the bulb: Institutional evolution and the phased ban of incandescent lighting in Germany. Energy Policy 67, 737-746.

Huenteler, J., Schmidt, T.S., Ossenbrink, J., Hoffmann, V.H., 2016. Technology lifecycles in the energy sector - Technological characteristics and the role of deployment for innovation. Technological Forecasting and Social Change 104, 102-121. 
Jacobsson, S., 2008. The emergence and troubled growth of a 'biopower' innovation system in Sweden. Energy Policy 36, 1491-1508.

Jacobsson, S., Bergek, A., 2004. Transforming the energy sector: the evolution of technological systems in renewable energy technology. Industrial and Corporate Change 13, 815-849.

Jacobsson, S., Bergek, A., 2011. Innovation system analyses and sustainability transitions: Contributions and suggestions for research. Environmental Innovation and Societal Transitions 1, 41-57.

Jarvenpaa, H.M., Makinen, S.J., 2008. An empirical study of the existence of the Hype Cycle: A case of DVD technology, 2008 IEEE International Engineering Management Conference, pp. 1-5.

Johnson, A., 2001. Functions in Innovation System Approaches, Nelson and Winter Conference. Danish Research Unit for Industrial Dynamics, DRUID, Aalborg.

Johnstone, P., Hielscher, S., 2017. Phasing out coal, sustaining coal communities? Living with technological decline in sustainability pathways. The Extractive Industries and Society 4, 457-461.

Kaplan, S., Tripsas, M., 2008. Thinking about technology: Applying a cognitive lens to technical change. Research Policy 37, 790-805.

Kivimaa, P., Kern, F., 2016. Creative destruction or mere niche support? Innovation policy mixes for sustainability transitions. Research Policy 45, 205-217.

Klepper, S., 1997. Industry Life Cycles. Industrial and Corporate Change 6, 145-182.

Konrad, K., Markard, J., Ruef, A., Truffer, B., 2012. Strategic responses to fuel cell hype and disappointment. Technological Forecasting and Social Change 79, 1084-1098.

Kukk, P., Moors, E.H.M., Hekkert, M.P., 2015. The complexities in system building strategies - The case of personalized cancer medicines in England. Technological Forecasting and Social Change 98, 47-59.

Lamberg, J.-A., Ojala, J., Peltoniemi, M., 2017. Thinking about industry decline: A qualitative meta-analysis and future research directions. Business History, 1-30.

Lauber, V., Jacobsson, S., 2016. The politics and economics of constructing, contesting and restricting socio-political space for renewables - The German Renewable Energy Act. Environmental Innovation and Societal Transitions 18, 147-163.

Lazonick, W., 1983. Industrial Organization and Technological Change: The Decline of the British Cotton Industry. Business History Review 57, 195-236.

Markard, J., in press. The next phase of the energy transition and its implications for research and policy. Nature Energy.

Markard, J., Hekkert, M., Jacobsson, S., 2015. The technological innovation systems framework: Response to six criticisms. Environmental Innovation and Societal Transitions 16, 76-86.

Markard, J., Hoffmann, V.H., 2016. Analysis of complementarities: Framework and examples from the energy transition. Technological Forecasting and Social Change 111, 63-75.

Markard, J., Raven, R., Truffer, B., 2012. Sustainability Transitions: An emerging field of research and its prospects. Research Policy 41, 955-967.

Markard, J., Truffer, B., 2008. Technological innovation systems and the multi-level perspective: towards an integrated framework. Research Policy 37, 596-615.

Markard, J., Wirth, S., Truffer, B., 2016. Institutional dynamics and technology legitimacy: A framework and a case study on biogas technology. Research Policy 45, 330-344. 
McGahan, A., Argyres, N., Baum, J.A.C., 2004. Context, technology and strategy: Forging new perspectives on the industry life cycle, Business Strategy over the Industry Lifecycle. Emerald Group Publishing Limited, pp. 1-21.

McKinsey, 2012. Lighting the way: Perspectives on the global lighting market. McKinsey \& Company, Vienna.

Murmann, J.P., Frenken, K., 2006. Toward a systematic framework for research on dominant designs, technological innovations, and industrial change. Research Policy 35, 925-952.

Musiolik, J., Markard, J., 2011. Creating and shaping innovation systems: Formal networks in the innovation system for stationary fuel cells in Germany. Energy Policy 39, 1909-1922.

Musiolik, J., Markard, J., Hekkert, M., Furrer, B., 2018. Creating innovation systems: How resource constellations affect the strategies of system builders. Technological Forecasting and Social Change (this issue).

Negro, S., Hekkert, M., Smits, R., 2007. Explaining the failure of the Dutch innovation system for biomass digestion - a functional analysis. Energy Policy 35, 925-938.

Negro, S., Hekkert, M.P., 2008. Explaining the success of emerging technologies by innovation system functioning: the case of biomass digestion in Germany. Technology Analysis \& Strategic Management 20, 465 - 482.

Nelson, R.R., 1995. Co-evolution of Industry Structure, Technology and Supporting Institutions, and the Making of Comparative Advantage. International Journal of the Economics of Business 2, 171-184.

Pavitt, K., 1984. Sectoral patterns of technical change: Towards a taxonomy and a theory. Research Policy 13, 343-373.

Peltoniemi, M., 2011. Reviewing Industry Life-cycle Theory: Avenues for Future Research. International Journal of Management Reviews 13, 349-375.

Penna, C.C.R., Geels, F.W., 2012. Multi-dimensional struggles in the greening of industry: A dialectic issue lifecycle model and case study. Technological Forecasting and Social Change 79, 999-1020.

Raven, R., Verbong, G., 2007. Multi-regime interactions in the Dutch energy sector. The case of combined heat and power technologies in the Netherlands 1970-2000. Technology Analysis \& Strategic Management 19, 491-507.

Rip, A., Kemp, R., 1998. Technological Change, in: Rayner, S., Malone, E.L. (Eds.), Human choice and climate change - Resources and technology. Battelle Press, Columbus, pp. 327-399.

Rosenbloom, D., in press. Framing low-carbon pathways: A discursive analysis of contending storylines surrounding the phase-out of coal-fired power in Ontario. Environmental Innovation and Societal Transitions.

Rosenbloom, D., Berton, H., Meadowcroft, J., 2016. Framing the sun: A discursive approach to understanding multi-dimensional interactions within socio-technical transitions through the case of solar electricity in Ontario, Canada. Research Policy 45, 1275-1290.

Sandén, B.A., Hillman, K.M., 2011. A framework for analysis of multi-mode interaction among technologies with examples from the history of alternative transport fuels in Sweden. Research Policy 40, 403-414.

Smink, M.M., Hekkert, M.P., Negro, S.O., 2015. Keeping sustainable innovation on a leash? Exploring incumbents' institutional strategies. Business Strategy and the Environment 24, 86-101. 
Stegmaier, P., Kuhlmann, S., Visser, V.R., 2014. The discontinuation of socio-technical systems as a governance problem, in: Borrás, S., Edler, J. (Eds.), The governance of socio-technical systems. Edward Elgar, Cheltenham, pp. 111-131.

Stegmaier, P., Visser, V.R., Kuhlmann, S., 2012. Governance of the discontinuation of socio-technical systems - An exploratory study of the incandescent light bulb phaseout. 4S/EASST Conference, Copenhagen, October 17-20.

Stephan, A., Schmidt, T.S., Bening, C.R., Hoffmann, V.H., 2017. The sectoral configuration of technological innovation systems: Patterns of knowledge development and diffusion in the lithium-ion battery technology in Japan. Research Policy in press.

Suarez, F.F., Grodal, S., Gotsopoulos, A., 2015. Perfect timing? Dominant category, dominant design, and the window of opportunity for firm entry. Strategic Management Journal 36, 437-448.

Taylor, M., Taylor, A., 2012. The technology life cycle: Conceptualization and managerial implications. International Journal of Production Economics 140, 541-553.

Turnheim, B., Geels, F.W., 2012. Regime destabilisation as the flipside of energy transitions: Lessons from the history of the British coal industry (1913-1997). Energy Policy 50, 35-49.

Tushman, M.L., Rosenkopf, L., 1992. Organizational Determinants of Technological Change: Toward a Sociology of Technological Evolution. Research in Organizational Behavior 14, 311-347.

Utterback, J.M., Abernathy, W.J., 1975. A dynamic model of process and product innovation. Omega 3, 639-656.

Vahl, F.P., Campos, L.M.S., Casarotto Filho, N., 2013. Sustainability constraints in techno-economic analysis of general lighting retrofits. Energy and Buildings 67, 500507.

Vuori, T.O., Huy, Q.N., 2016. Distributed Attention and Shared Emotions in the Innovation Process. Administrative Science Quarterly 61, 9-51.

Wesseling, J.H., Farla, J.C.M., Sperling, D., Hekkert, M.P., 2014. Car manufacturers' changing political strategies on the ZEV mandate. Transportation Research Part D: Transport and Environment 33, 196-209.

Wirth, S., Markard, J., 2011. Context matters: How existing sectors and competing technologies affect the prospects of the Swiss Bio-SNG innovation system. Technological Forecasting and Social Change 78, 635-649.

Wirth, S., Markard, J., Truffer, B., Rohracher, H., 2013. Informal institutions matter: Professional culture and the development of biogas technology. Environmental Innovation and Societal Transitions 8, 20-41. 